\title{
Element-Selective Molecular Charge Transport Characteristics of Binuclear Copper(II)-Lanthanide(III) Complexes
}

\author{
Sebastian Schmitz, ${ }^{[a]}$ Andrew Kovalchuk, ${ }^{[b]}$ Alejandro Martín-Rodríguez, ${ }^{[c]}$ Jan van Leusen, ${ }^{[a]}$ \\ Natalya V. Izarova, ${ }^{[\mathrm{d}]}$ Svenja D. M. Bourone, ${ }^{[\mathrm{a}]}$ Yong Ai, ${ }^{[\mathrm{b}]}$ Eliseo Ruiz, ${ }^{[\mathrm{c}]}$ Ryan C. Chiechi, *[b] \\ Paul Kögerler, ${ }^{*[a],[d]}$ and Kirill Yu. Monakhov*[a] \\ ${ }^{[a]}$ Institut für Anorganische Chemie, RWTH Aachen University, Landoltweg 1, 52074 Aachen (Germany). \\ ${ }^{[b]}$ Stratingh Institute for Chemistry \& Zernike Institute for Advanced Materials, University of Groningen, Nijenborgh 4, \\ Groningen 9747 AG (Netherlands). \\ ${ }^{[c]}$ Departament de Química Inorgànica i Orgànica and Institut de Química Teòrica i Computacional, Universitat de Barce- \\ lona, Diagonal 645, 08028 Barcelona (Spain). \\ [d] Jülich-Aachen Research Alliance (JARA-FIT) and Peter Grünberg Institute (PGI-6), Forschungszentrum Jülich GmbH, \\ Wilhelm-Johnen-Straße, 52425 Jülich (Germany).
}

Keywords: $3 d-4 f$ coordination compounds $\bullet$ magnetochemistry $\bullet$ self-assembled monolayers $\bullet$ molecular conductivity • density functional theory calculations

\begin{abstract}
A series of isostructural dinuclear $3 \mathrm{~d}-4 \mathrm{f}$ complexes, isolated as [CuLn(L·SMe $\left.)_{2}(\mathrm{OOCMe})_{2}\left(\mathrm{NO}_{3}\right)\right] \cdot x M e O H(\mathrm{Ln}=\mathrm{Gd} \mathbf{1}$, $\mathrm{Tb} 2$, Dy 3 and $Y 4 ; x=0.75-1)$ and comprising one acetate and two thioether-Schiff base (L·SMe ${ }^{-}$) bridging ligands based on 4(methylthio)aniline and 2-hydroxy-3-methoxybenzaldehyde ( $\mathrm{HL} \cdot \mathrm{SMe}=\mathrm{C}_{15} \mathrm{H}_{15} \mathrm{NO}_{2} \mathrm{~S}$ ), was synthesized and fully characterized. The magnetic properties of the charge-neutral $\{C u L n\}$ complexes are dominated by ferromagnetic Cu"-Ln'" exchange interactions. Large-area electron transport studies reveal that the average conductivity of robust, self-assembled \{CuLn\} monolayers on a gold substrate is significantly lower than that of common alkane thiolates. Theoretical calculations of transmission spectra of individual complexes $\mathbf{1}$ and $\mathbf{4}$ embedded between two metallic electrodes show that the molecular current-voltage (I$V)$ characteristics are strongly influenced by electron transport through the $\mathrm{Cu}$ centers and thus fully independent on the lanthanide ion, in excellent agreement with the experimental $I-V$ data for 1-4. The $\beta$-polarized transmission indicated by calculations of $\mathbf{1}$ and $\mathbf{4}$ points out their potential as spin filters. In addition, the reactivity of the title compound $\mathbf{1}$ with $\mathrm{Cu}^{\prime \prime}$ in a square-pyramidal coordination environment toward methanolate and azide was examined, resulting in the formation of a linear trinuclear complex, $\left[\mathrm{Cu}_{2} \mathrm{Na}(\mathrm{L} \cdot \mathrm{SMe})_{4}\right] \mathrm{NO}_{3} \cdot 3 \mathrm{MeOH}(5)$, characterized by antiferromagnetic exchange interactions between the two copperions.
\end{abstract}

\section{INTRODUCTION}

Formation of thin films consisting of magnetic coordination complexes ${ }^{1}$ and analysis of their charge transport characteristics with controlled conductance switching defines an important niche in the development of molecular spintronics. ${ }^{2-6}$ In such experiments, changing the nature of top and bottom metallic contact electrodes allows us to create specific measurement environments for assessing and modifying the large-area charge- and spin-dependent transport properties of self-assembly monolayers (SAMs). Such electrical measurements can be performed for common molecular tunnel junctions, (e.g., Au ${ }^{\text {bottom_SAM- }}$ $\mathrm{Au}^{\text {top }}$ ), spin-polarized junctions ${ }^{9}$ (e.g., $\mathrm{Au}^{\text {bottom }}-\mathrm{SAM}-$ ferromagnetic $\mathrm{Ni}^{\text {top }}$ ) or hybrid systems involving a confor-

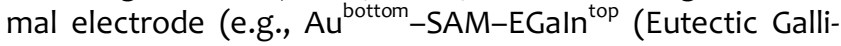
um-Indium) $)^{10,11}$ The latter approach offers particularly interesting perspectives for studying large-area tunneling charge transport ${ }^{12}$ across magnetic SAMs, comparing their mechanical ${ }^{13,14}$ and electrical properties to those of e.g. widely investigated alkanethiol SAMs. ${ }^{15}$ Herein we aim to determine the adsorption characteristics and the main transmission channel of $3 \mathrm{~d}-4 \mathrm{f}$ coordination compounds characterized by intrinsically distinct magnetic states that are differently disposed relative to the Fermi levels of the metallic electrodes in the fabricated $\mathrm{Au}^{\text {bottom }}$-heterometal complex-EGaln ${ }^{\text {top }}$ junctions. Specifically, we focus on copper-lanthanide systems ${ }^{16-24}$ that have shown to exhibit structural motifs of varying complexity ${ }^{25}$ and interesting magnetic and electrical conductivity properties.

We herein report the preparation, magnetochemistry, adsorption characteristics and electrical transport properties of a family of thioether-augmented Schiff base/carboxylate copper(II)-lanthanide(III) complexes of general formula $\left[\mathrm{CuLn}(\mathrm{L} \cdot \mathrm{SMe})_{2}(\mathrm{OOCMe})_{2}\left(\mathrm{NO}_{3}\right)\right] \cdot x \mathrm{MeOH}(\mathrm{Ln}=\mathrm{Gd} \mathbf{1}, \mathrm{Tb} 2$, Dy 


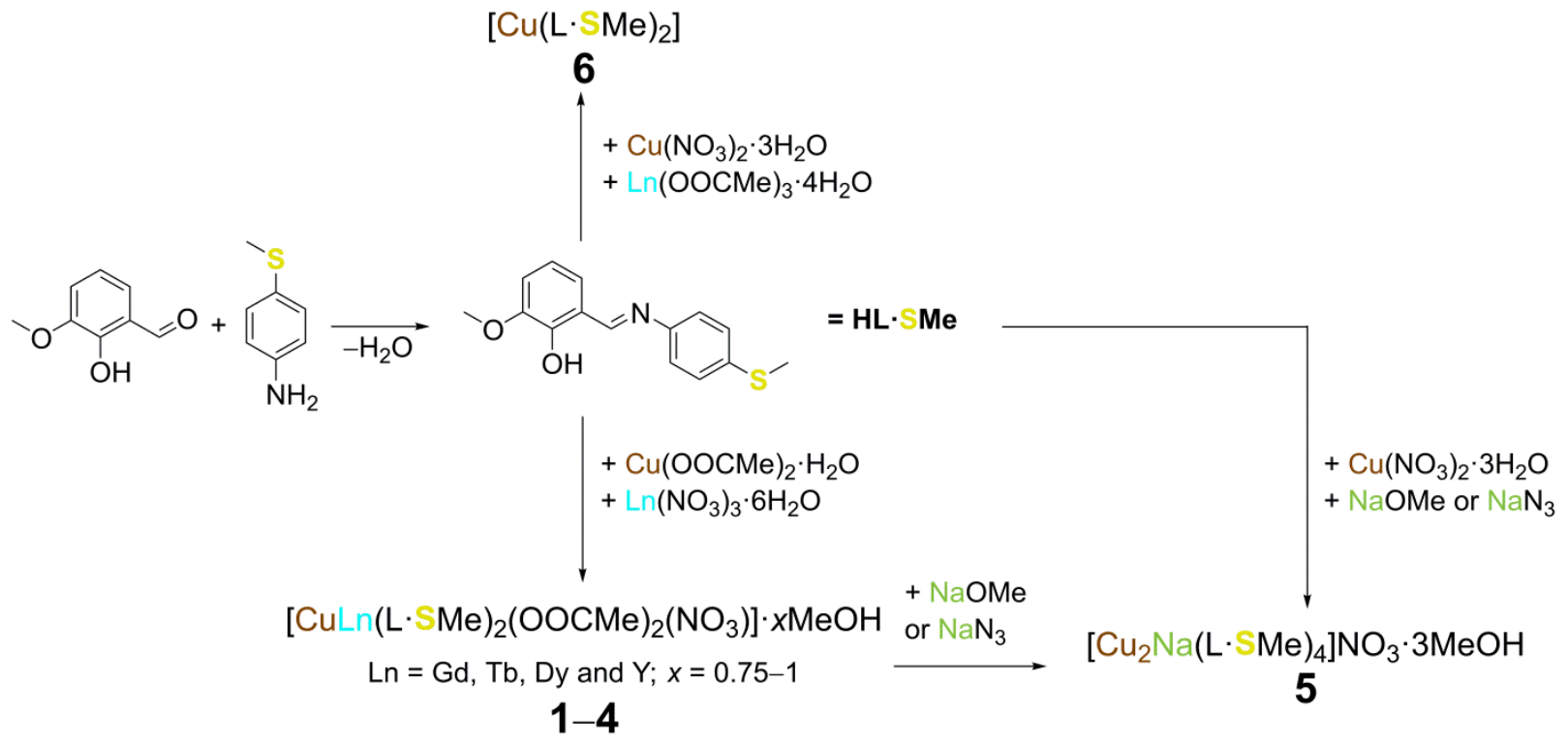

Scheme 1. Synthesis of the tetradentate Schiff base HL.SMe $\left(=\mathrm{C}_{15} \mathrm{H}_{15} \mathrm{NO}_{2} \mathrm{~S}\right)$ and compounds 1-6.

3 and $Y$ 4; $x=0.75-1$ ). With an undercoordinated copper center, the ability to modify its coordination geometry upon reaction with smaller ligands was assessed and the resulting trimetallic, lanthanide-free compound $\left[\mathrm{Cu}_{2} \mathrm{Na}(\mathrm{L} \cdot \mathrm{SMe})_{4}\right] \mathrm{NO}_{3} \cdot 3 \mathrm{MeOH}$ (5) was analyzed. Both the novel Schiff base HL.SMe and its metal coordination products were characterized using ${ }^{1} \mathrm{H}$ and ${ }^{13} \mathrm{C}$ nuclear magnetic resonance (NMR), infrared (IR) spectroscopy, electrospray ionization mass spectrometry (ESI-MS), thermogravimetric analysis (TGA), and single-crystal X-ray diffraction. The molecular deposition and the formation of thin films of compounds 1-4 on a gold substrate was studied via infrared reflection-absorption spectroscopy (IRRAS), ellipsometry and scanning tunneling microscopy (STM) combined with an EGaln tip to form molecular junctions. These large-area transport measurements were accompanied by density functional theory (DFT) calculations in order to gain a deeper insight into the conductivity peculiarities at the targeted bottom electrode-heterometal complex-top electrode interfaces.

\section{RESULTS AND DISCUSSION}

Synthesis and Stability. Compounds 1-4 were synthesized under aerobic conditions using a two-step synthetic procedure (Scheme 1). The freshly prepared Schiff base HL-SMe was first reacted in methanol under basic conditions, using triethylamine $\left(\mathrm{Et}_{3} \mathrm{~N}\right)$ as base, together with lanthanide nitrate hexahydrates, $\mathrm{Ln}\left(\mathrm{NO}_{3}\right)_{3} \cdot 6 \mathrm{H}_{2} \mathrm{O}(\mathrm{Ln}=\mathrm{Gd}$, Tb, and $\mathrm{Dy})$, or yttrium hexahydrate, $\mathrm{Y}\left(\mathrm{NO}_{3}\right)_{3} \cdot 6 \mathrm{H}_{2} \mathrm{O}$ (as diamagnetic analogue) in a $2.0: 2.3: 1.0$ molar ratio under reflux conditions for 15 minutes. A 1.0 eq. of copper acetate monohydrate (based on $\mathrm{Cu}$ ), $\left[\mathrm{Cu}_{2}(\mathrm{OOCMe})_{4}\left(\mathrm{H}_{2} \mathrm{O}\right)_{2}\right]$, was subsequently added to the resulting clear orange solution that immediately changed to a dark brown color. After stirring under reflux conditions for further 60 minutes the dark brown solution was filtered off and the filtrate was stored in a capped vial under ambient atmosphere, precipitating the crystalline title compounds $\left[\mathrm{CuLn}(\mathrm{L} \cdot \mathrm{SMe})_{2}(\mathrm{OOCMe})_{2}\left(\mathrm{NO}_{3}\right)\right] \cdot x \mathrm{MeOH}(\mathrm{Ln}=\mathrm{Gd} \mathbf{1}, \mathrm{Tb} 2$, Dy 3 and $Y 4 ; x=0.75-1)$ in moderate-to-good yields after one day (24.2\% for 4 and $31.3-74.0 \%$ for $1-3)$. We note that earlier lanthanide precursors (with $\mathrm{Ln}^{3+}$ ions larger than $\mathrm{Gd}^{3+}$ ) did not yield any product precipitation within the time frame described for 1-4 (see Experimental Section). Bigger lanthanides might lead to ligand rearrangement, which stabilizes their coordination more efficiently. (Bigger lanthanides might lead to a formation of a different $3 \mathrm{~d}-4 \mathrm{f} \mathrm{co-}$ ordination complex under other crystallization conditions, which is for their size more stable.) Compounds 1-4 are stable under air and moisture. According to TGA curves (see Supporting Information), the solvent-free compounds 1-4 only degrade above ca. $220{ }^{\circ} \mathrm{C}$ under $\mathrm{N}_{2}$ atmosphere or in air, and in that they are slightly more stable than the $\mathrm{HL}$.SMe ligand ( $\mathrm{ca} .200{ }^{\circ} \mathrm{C}$ ). It is noteworthy that changing the reaction components in the above-mentioned synthetic process by replacing $\mathrm{Ln}\left(\mathrm{NO}_{3}\right)_{3} \cdot 6 \mathrm{H}_{2} \mathrm{O}$ with $\mathrm{Ln}(\mathrm{OOCMe})_{3} \cdot 4 \mathrm{H}_{2} \mathrm{O}$ and $\left[\mathrm{Cu}_{2}(\mathrm{OOCMe})_{4}\left(\mathrm{H}_{2} \mathrm{O}\right)_{2}\right]$ with $\mathrm{Cu}\left(\mathrm{NO}_{3}\right)_{2} \cdot 3 \mathrm{H}_{2} \mathrm{O}$ does not result in compounds 1-4. Although these reactions are characterized by the same color gradient, they produce a neutral mononuclear compound 6 with the formula $\left[\mathrm{Cu}(\mathrm{L} \cdot \mathrm{SMe})_{2}\right]$ (for details see the Supporting Information), likely due to the lower solubility of the lanthanide acetate precursors (vs. the lanthanide nitrates). This complex can also be obtained by the direct reaction of the Schiff base ligand with common copper(II) salts in a 1:1 ratio in methanol.

The positive ion-mode ESI mass spectra of acetonitrile solutions of compounds 1-4 (see Supporting Information) exhibit the molecular mass peak of the $\left[\mathrm{CuLn}(\mathrm{L} \cdot \mathrm{SMe})_{2}(\mathrm{OOCMe})_{2}\right]^{+}$fragment without a $\mathrm{NO}_{3}{ }^{-}$ion at $\mathrm{m} / \mathrm{z} 814.012$ (4) - 889.059 (3). These molecular masses are 
detected in different intensities depending on the particular lanthanide ion ( $1=69 \% ; 2=100 \% ; 3=52 \%$ and $4=100 \%$ ). Interestingly, the $\mathrm{m} / \mathrm{z}$ patterns also indicate the presence of the $\left[\mathrm{CuNa}(\mathrm{L} \cdot \mathrm{SMe})_{2}\right]^{+}$fragment at $\mathrm{m} / \mathrm{z} 630.068-630.086$ and of the $\left[\mathrm{Cu}_{2}(\mathrm{~L} \cdot \mathrm{SMe})_{3}\right]^{+}$fragment at $\mathrm{m} / \mathrm{z} 944.081$ 944.110. The molecular mass peak of $\left[\mathrm{CuNa}(\mathrm{L} \cdot \mathrm{SMe})_{2}\right]^{+}$ demonstrates that complexes 1-4 are coordinatively labile against sodium salts, as also evident from the synthesis (Scheme 1). The detection of this fragment by ESI-MS and the square-pyramidal $\mathrm{Cu}^{\prime \prime}$ environment with one vacant coordination side in 1-4 prompted us to tune the structural and physical properties of these complexes by reacting them with simple sodium salts such as $\mathrm{NaOMe}$ and $\mathrm{NaN}_{3}$. The addition of these to a methanolic solution of freshly prepared 1-4 in a $2.6: 1.0$ ( $\{C u L n\}$ : ligand) molar ratio leads to the formation of a trinuclear compound with the formula $\left[\mathrm{Cu}_{2} \mathrm{Na}(\mathrm{L} \cdot \mathrm{SMe})_{4}\right] \mathrm{NO}_{3} \cdot 3 \mathrm{MeOH}(5)$, which in its solvent-free state is slightly less thermally stable (up to ca. $200{ }^{\circ} \mathrm{C}$ ) than 1-4 (see Supporting Information). 5 can also be obtained directly by reacting $\mathrm{HL} \cdot \mathrm{SMe}$ with triethylamine and $\mathrm{Cu}\left(\mathrm{NO}_{3}\right)_{2} \cdot 3 \mathrm{H}_{2} \mathrm{O}$ in a $2.0: 2.3: 1.0$ ratio at $65^{\circ} \mathrm{C}$ in $\mathrm{MeOH}$ and the subsequent reaction of the formed dark-brown solution with 1.0 eq. of NaOMe under reflux conditions. The ESI-MS spectrum of an acetonitrile solution of compound $\mathbf{5}$ (see Supporting Information) shows the molecular mass peak of $\left[\mathrm{CuNa}(\mathrm{L} \cdot \mathrm{SMe})_{2}\right]^{+}$at $\mathrm{m} / \mathrm{z} 630.068$ with $100 \%$ intensity. Additionally, the mass spectrum displays the expected molecular mass peak of the monocationic fragment $\left[\mathrm{Cu}_{2} \mathrm{Na}(\mathrm{L} \cdot \mathrm{SMe})_{4}\right]^{+}$at $\mathrm{m} / \mathrm{z} 1239.144$ with $50 \%$ intensity. Although $\mathrm{m} / \mathrm{z} 1237.146$ is expected to be the most intense monoisotopic mass, due to the isotopic distribution several signals around $\mathrm{m} / \mathrm{z} 1239$ add up to a more intense peak than the former.

X-ray Diffraction Structural Analysis. Since compounds 1-4 are quasi-isostructural (Figure 1) and crystallize in the triclinic space group $P_{-1}$ (see Tables S2 and S3 in the Supporting Information), we here describe the structural parameters of only the $\mathrm{Gd}$ derivate (1) as a representative example. All neutral bimetallic complexes $\left[\mathrm{CuLn}(\mathrm{L} \cdot \mathrm{SMe})_{2}(\mathrm{OOCMe})_{2}\left(\mathrm{NO}_{3}\right)\right](\mathrm{Ln}=\mathrm{Gd}, \mathrm{Tb}$, Dy and $\mathrm{Y})$ comprise a nine-coordinated lanthanide(III) or yttrium(III) ion and a copper(II) ion in a square-pyramidal $\mathrm{N}_{2} \mathrm{O}_{3}$ coordination environment. The metal centers are bridged by two deprotonated tridentate Schiff base ligands $\left(\mathrm{L} \cdot \mathrm{SMe} \mathrm{C}^{-}\right.$) and an acetate ligand (Gd-Oacetate: 2.316(4) $\AA$; Cu-Oacetate: 2.196(4) $\AA$ ). The coordination polyhedron around the lanthanide (or yttrium) center is completed by chelating terminal nitrate $\left(\mathrm{Gd}-\mathrm{O}_{\mathrm{NO}_{3}}: 2.508(4)-2.517(4) \AA\right)$ and acetate ligands (Gd-Oacetate: 2.432(4) - 2.476(4) $\AA$ ). Each Schiff base ligand $\mathrm{L} \cdot \mathrm{SMe}^{-}$is attached to the $\mathrm{Ln}^{\prime \prime \prime} / \mathrm{Y}^{\prime \prime \prime}$ center via its -OMe group (Gd-Oether: 2.474(4) - 2.578(4) ^) and deprotonated $\mathrm{O}_{\text {alc }}$ atom of the alcohol group at the aryl ring (Gd-Oalc: $2.302(4)-2.353(4) \AA)$. The latter and an imine group of the $\mathrm{L} \cdot \mathrm{SMe}^{-}$bind to the $\mathrm{Cu}^{\prime \prime}$ ion $\left(\mathrm{Cu}-\mathrm{O}_{\mathrm{alc}}: 1.957(4)-1.962(4) \AA\right.$ and $\mathrm{Cu}-\mathrm{N}_{\text {imine }}$ : 1.998(5) - 2.012(4) $\AA$ ). The non-bonding Gd...Cu distance is 3.3960 (8) $\AA$. The $S$ atoms of two thioether groups at the periphery of the structure are separated by $5.57 \AA$. Importantly, these thioether groups are not involved in any intermolecular coordinative bond in the crystal lattice. ${ }^{26,27}$



Figure 1. Molecular structure of compounds 1-4. Hydrogen atoms and crystal solvent molecules are omitted for clarity. Color code: $\mathrm{C}$ of L·SMe- : gray, $\mathrm{C}$ of acetate: green, Cu: brown, Ln/Y: turquoise, $\mathrm{N}$ : blue, O: red, S: yellow.

Compound 5 crystallizes in the monoclinic space group $P 2_{1} / c$ (see Supporting Information, Table S3). The monocationic $\left[\mathrm{Cu}_{2} \mathrm{Na}(\mathrm{L} \cdot \mathrm{SMe})_{4}\right]^{+}$fragment of this complex shows a nearly linear structure with a $\mathrm{Cu}-\mathrm{Na}-\mathrm{Cu}$ angle of $178.75(6)^{\circ}$ (Figure $2)$. The structure consists of two $\mathrm{Cu}^{\mathrm{II}}$ ions in distorted planar $\mathrm{N}_{2} \mathrm{O}_{2}$ environments separated by an octacoordinated sodium ion, with non-bonding $\mathrm{Cu} \cdots \mathrm{Na}$ and $\mathrm{Cu} \cdot \cdots \mathrm{Cu}$ distances of $3.407 \AA$ and $6.813 \AA$, respectively. The molecular structure is supported by four L.SMe ${ }^{-}$ligands, with two remote thioether groups lying roughly in the same plane as the metal centers. The shortest S...S distances are $5.04 \AA$ and $6.25 \AA$, while the longest one between two sulfur atoms at opposite sides of $\left[\mathrm{Cu}_{2} \mathrm{Na}(\mathrm{L} \cdot \mathrm{SMe})_{4}\right]^{+}$is $19.46 \AA$. Each Cu" center is coordinated by two nitrogen atoms ( $\mathrm{Cu}-\mathrm{N}_{\text {imine }}$ : 1.964(3) 1.972(4) $\AA$ ) and two deprotonated $\mathrm{O}_{\mathrm{alc}}$ atoms of the alcohol groups ( $\mathrm{Cu}-\mathrm{O}_{\mathrm{alc}}: 1.887(3)-1.903(3) \AA$ ) at the aryl rings of the adjacent $\mathrm{L} \cdot \mathrm{SMe} \mathrm{e}^{-}$ligands. The distorted coordination environment of the central $\mathrm{Na}^{+}$ion is saturated by four deprotonated $\mathrm{O}_{\mathrm{alc}}$ atoms ( $\left.\mathrm{Na}-\mathrm{O}_{\mathrm{alc}}: 2.319(3)-2.415(4) \AA\right)$ and four -OMe groups ( $\left.\mathrm{Na}-\mathrm{O}_{\text {ether: }} 2.568(4)-2.685(4) \AA\right)$ of all $\mathrm{L} \cdot \mathrm{SMe}^{-}$ligands. The charged $\left[\mathrm{Cu}_{2} \mathrm{Na}(\mathrm{L} \cdot \mathrm{SMe})_{4}\right]^{+}$species is counterbalanced by a $\mathrm{NO}_{3}^{-}$anion.

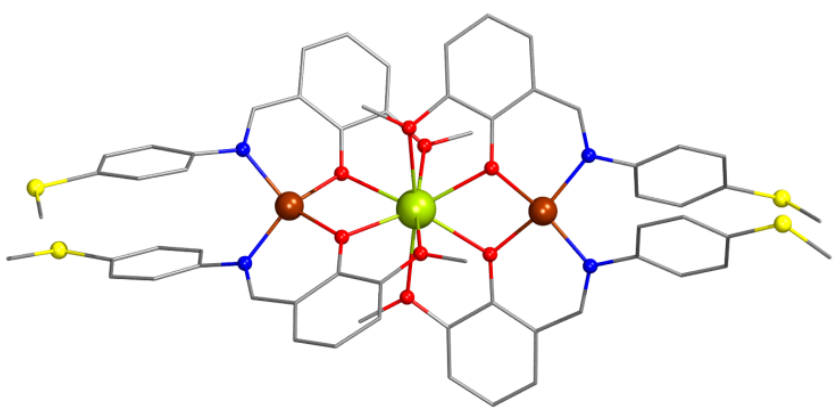

Figure 2. Molecular structure of $\left[\mathrm{Cu}_{2} \mathrm{Na}(\mathrm{L} \cdot \mathrm{SMe})_{4}\right]^{+}$in 5 . Hydrogen atoms, crystal solvent molecules and a nitrate counterion are 
omitted for clarity. Color code: $\mathrm{C}=$ gray, $\mathrm{Cu}=$ brown, $\mathrm{N}=$ blue, $\mathrm{Na}=$ lime green, $\mathrm{O}=$ red, $\mathrm{S}=$ yellow .

Magnetism and Magnetochemical Modeling. The magnetic susceptibilities of compounds $\mathbf{1 - 5}$ are shown in Figure 3 as $\chi_{\mathrm{m}} T$ vs. $T$ and $M_{\mathrm{m}}$ vs. $B$ plots. At $290 \mathrm{~K}$ and $0.1 \mathrm{~T}$, the $\chi_{\mathrm{m}} T$ values of the four compounds 1-4 are well within or close to the upper limit of the expected range for a copper center and the respective lanthanide center, which are not interacting: 1: 8.44 (expected: ${ }^{28} 7.97-8.42$ ), 2: 12.08 (12.0 12.5 ), 3: 14.14 (13.4 - 14.7), 4: $0.46(0.36-0.61) \mathrm{cm}^{3} \mathrm{~K} \mathrm{~mol}^{-1}$. Upon decreasing the temperature, the $\chi_{\mathrm{m}} T$ curves of the compounds reveal different characteristics. For $\mathbf{4}$, where a diamagnetic $\mathrm{Y}^{3+}$ center substitutes the paramagnetic $\mathrm{Ln}^{3+}$ centers of 1-3, $\chi_{\mathrm{m}} T$ gradually decreases to $0.43 \mathrm{~cm}^{3} \mathrm{~K} \mathrm{~mol}^{-1}$ at $14.0 \mathrm{~K}$, and subsequently rapidly decreases to $0.40 \mathrm{~cm}^{3} \mathrm{~K} \mathrm{~mol}^{-1}$ at $2.0 \mathrm{~K}$. While the first decrease is due to the single-ion effect of the $\mathrm{Cu}^{2+}$ center (thermal depopulation of the energy states split by a quadratic pyramidal ligand field in addition to mixing of these states due to spinorbit coupling), the second cannot be caused primarily by Zeeman splitting, considering the weak applied field of $0.1 \mathrm{~T}$, but is most likely due to very weak inter-molecular exchange interactions present within the solid state. The molar magnetization at $2.0 \mathrm{~K}$ increases to $1.0 \mathrm{~N}_{\mathrm{A}} \mu_{\mathrm{B}}$ at 5.0 T without reaching saturation. For $\mathbf{1}$, the $\mathrm{Gd}^{3+}$ center is, to a very good approximation, a pure $S=7 / 2$ center. By cooling the compound, $\chi_{\mathrm{m}} T$ continuously increases and shows three maxima, dependent on the applied field $\left(9.97 \mathrm{~cm}^{3} \mathrm{~K} \mathrm{~mol}^{-1}\right.$ at $0.1 \mathrm{~T}$ and $5.5 \mathrm{~K}, 9.60 \mathrm{~cm}^{3} \mathrm{~K} \mathrm{~mol}^{-1}$ at $1.0 \mathrm{~T}$ and $10.0 \mathrm{~K}$, $8.99 \mathrm{~cm}^{3} \mathrm{~K} \mathrm{~mol}^{-1}$ at $3.0 \mathrm{~T}$ and $20.0 \mathrm{~K}$ ), indicating ferromagnetic exchange interactions between the $\mathrm{Cu}^{2+}$ and the $\mathrm{Gd}^{3+}$ center. The shift of these maxima to higher temperatures with increasing fields, and the subsequent sharp decrease of $\chi_{m} T$ are due to the Zeeman splitting and the corresponding thermal depopulation of the energy states of both centers. As for $\mathbf{4}$, the molar magnetization of $\mathbf{1}$ is not saturated at $2.0 \mathrm{~K}$ and 5.0 T. The respective value of $8.0 \mathrm{~N}_{\mathrm{A}} \mu_{\mathrm{B}}$ is, however, close to the expected saturation value of ca. 8.1 $\mathrm{N}_{\mathrm{A}} \mu_{\mathrm{B}}$ $\left(M_{\mathrm{m}, \mathrm{sat}}=\left(\mathrm{g}_{\mathrm{Cu}} \cdot \mathrm{S}_{\mathrm{Cu}}+\mathrm{g}_{\mathrm{Gd}} \cdot \mathrm{S}_{\mathrm{Gd}}\right) N_{\mathrm{A}} \mu_{\mathrm{B}} \approx(1.1+7.0) N_{\mathrm{A}} \mu_{\mathrm{B}}\right), \mathrm{g}_{\mathrm{Cu}} \approx 2.2$ derived from the $\chi_{\mathrm{m}} T$ value of 4 at $\left.290 \mathrm{~K}\right)$. For $2, \chi_{\mathrm{m}} T$ stays almost constant down to $100 \mathrm{~K}$, slightly decreases upon further cooling to $10 \mathrm{~K}$, and drops sharply below $10 \mathrm{~K}$. We note the small change of the slope at about $30 \mathrm{~K}$ and the very sharp drop-off for $T<10 \mathrm{~K}$, which hints at weak ferromagnetic exchange interactions between the copper and $\mathrm{Tb}^{3+}$ centers. This is because the $\chi_{\mathrm{m}} T$ vs. $T$ curves of single $\mathrm{Tb}^{3+}$ centers, characterized by similar ligand fields, exhibit a more distinct decrease starting notably at $T<50 \mathrm{~K}$, and reach lower values at about $2.0 \mathrm{~K}$ due to the thermal depopulation of the (usually mixed) $m$, substates. The molar magnetization at $2.0 \mathrm{~K}$ is linear up to $c a .0 .5 \mathrm{~T}$, and reaches a value of $6.3 N_{A} \mu_{B}$ at 5.0 T. At this point, a significant slope characterizes the magnetization, which is therefore far from saturation. We estimate the contribution of the $\mathrm{Tb}^{3+}$ center for the given coordination geometry at 5.0 $\mathrm{T}$ as approximately half of the saturation value of the free $\mathrm{Tb}^{3+}$ ion $\left(M_{\mathrm{m}, \mathrm{sat}}=g_{J} \cdot J N_{\mathrm{A}} \mu_{\mathrm{B}}=9 N_{\mathrm{A}} \mu_{\mathrm{B}}\right)$ due to measuring the mean value (powder sample) of an anisotropic center. Taking into account the magnetization of the latter and $\mathbf{1}$, the value of $M_{\mathrm{m}}$ at 5.0 T is slightly above the sum of both contributions. Therefore, the field dependent data at $2.0 \mathrm{~K}$ are also in agreement with no or weak ferromagnetic exchange interactions between the $\mathrm{Cu}^{2+}$ center and the $\mathrm{Tb}^{3+}$ center. For 3, $\chi_{\mathrm{m}} T$ continuously decreases to a minimum at $20.0 \mathrm{~K}$ with decreasing temperature, subsequently increases to a maximum at $5.5 \mathrm{~K}$, and finally drops off sharply. In this case, the ferromagnetic exchange interactions between the $\mathrm{Cu}^{2+}$ center and the $\mathrm{Dy}^{3+}$ center are evident from the occurrence of the distinct maximum. The $M_{\mathrm{m}}$ vs. $B$ curve at $2.0 \mathrm{~K}$ is similar to the curve of $\mathbf{2}$ characterized by a steeper increase of the magnetization at lower fields. At $5.0 \mathrm{~T}, M_{m}$ is $6.4 N_{A} \mu_{B}$, slightly larger than the sum of the magnetization of $\mathbf{1}$ and half of the saturation magnetization of the free $\mathrm{Dy}^{3^{+}}$ion $\left(M_{\mathrm{m} \text {,sat }}=10 \mathrm{~N}_{\mathrm{A}} \mu_{\mathrm{B}}\right)$. Thus, the magnetization data are in agreement with the weak ferromagnetic exchange interactions deduced from the $\chi_{m} T$ vs. $T$ curve.
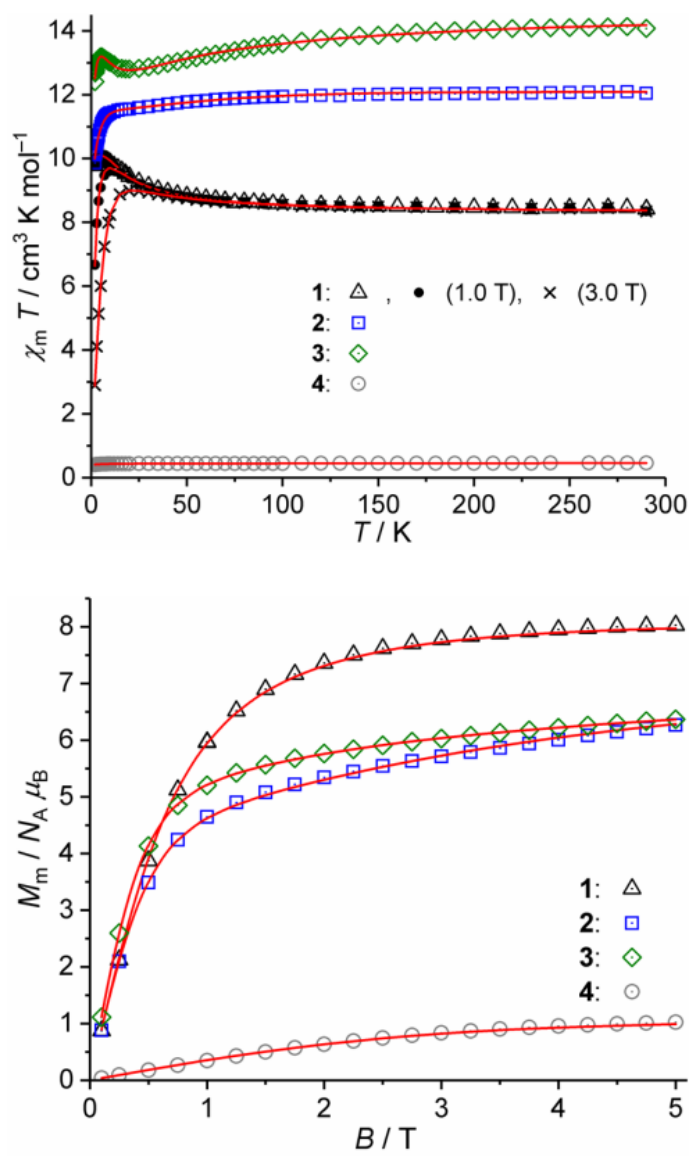

Figure 3. Temperature dependence of $\chi_{\mathrm{m}} T$ (top) and field dependence of the molar magnetization $M_{\mathrm{m}}$ (bottom) of 1-4; open symbols: experimental data at $0.1 \mathrm{~T}$ (top) and $2.0 \mathrm{~K}$ (bottom), respectively; solid red lines: least-squares fits.

To quantify the underlying magnetically relevant properties, we model the data employing the computational framework CONDON, ${ }^{29,30}$ which takes into account interelectronic repulsion, ligand field, spin-orbit coupling, Zeeman effect and Heisenberg-Dirac-van Vleck exchange interactions, by implementing the following strategies. We start 
by modeling the data of compound 4 to characterize the $\mathrm{Cu}^{2+}$ centers in 1-4. To generate starting values of the ligand field parameters, we assumed a ligand field symmetry of approximately $C_{4 v}$ during the calculations using the point charge electrostatic model (PCEM). While fitting the parameters to the data using the full basis of the $3 \mathrm{~d}^{9}$ electron configuration (10 energy states), the relation $B_{4}^{4} / B^{4}$ o was initially treated as constant. When the already good quality of the fit (SQ, relative root mean square error) did not improve any further, the relation was allowed to vary, yet only small deviations were found. During these steps, the signs of these parameters were set as derived from the PCEM. Finally, to account for the rapid decrease of $\chi_{m} T$ at $T<$ 14.0 K, a mean-field approach was chosen to model potential weak inter-molecular exchange interactions. The parameters of the least-squares fit are listed in Table 1. The parameters describe a $\mathrm{Cu}^{2+}$ ion in a square pyramidal ligand field, which exhibits very weak antiferromagnetic, intermolecular exchange interactions (characterized by $\left.z J^{\prime}\right)$. For the analyses of $\mathbf{1}-\mathbf{3}$, we assume the $\mathrm{Cu}^{2+}$ center to be identical to the one in 4 . We neglect, however, the very weak inter-molecular interactions, since the data here are dominated by the exchange interactions between the $\mathrm{Cu}^{2+}$ and $\mathrm{Ln}^{3+}$ centers.

Table 1. Magnetic quantities and fit parameters of 1-5: oneelectron spin-orbit coupling constant $\zeta$, Racah parameters $B$ and $C$, Slater-Condon parameters $F^{2}, F^{4}$ and $F^{6}$, ligand field parameters $B_{q}^{k}$ in Wybourne notation, mean-field ( $\left.z J^{\prime}\right)$ and exchange interaction $(J)$ parameters (both in " $-2 J$ " notation), all of which are stated in $\mathrm{cm}^{-1}$.

\begin{tabular}{|c|c|c|c|c|c|}
\hline & $\begin{array}{l}\mathrm{Cu}^{2+} \\
(1-4)\end{array}$ & $\begin{array}{l}G^{3+} \\
\text { (1) }\end{array}$ & $\begin{array}{l}\mathrm{Tb}^{3+} \\
(2)\end{array}$ & $\begin{array}{l}\text { Dy }^{3+} \\
\text { (3) }\end{array}$ & $\mathrm{Cu}^{2+}(5)$ \\
\hline$\zeta^{31,32}$ & 829 & --- & 1705 & 1900 & 829 \\
\hline$B^{31}$ & 1238 & --- & --- & --- & 1238 \\
\hline$c^{31}$ & 4659 & --- & --- & --- & 4659 \\
\hline$F^{232}$ & --- & --- & 97650 & 94500 & --- \\
\hline$F^{432}$ & --- & --- & 68531 & 66320 & --- \\
\hline$F^{632}$ & --- & --- & 52397 & 50707 & --- \\
\hline$B^{2}{ }_{0}$ & $\begin{array}{l}20871 \\
\pm 15\end{array}$ & --- & $\begin{array}{l}-467 \\
\pm 3\end{array}$ & $\begin{array}{l}-1207 \\
\pm 39\end{array}$ & $\begin{array}{l}-17837 \\
\pm 2946\end{array}$ \\
\hline$B^{4}{ }_{0}$ & $\begin{array}{l}26579 \\
\pm 11\end{array}$ & --- & $\begin{array}{l}-233 \pm \\
9\end{array}$ & $\begin{array}{l}-1790 \\
\pm 72\end{array}$ & $\begin{array}{l}13566 \\
\pm 1636\end{array}$ \\
\hline$B_{4}^{4}$ & $\begin{array}{l}45905 \\
\pm 9\end{array}$ & --- & $\begin{array}{l}-294 \\
\pm 6\end{array}$ & $\begin{array}{l}-1182 \\
\pm 11\end{array}$ & $\begin{array}{l}-49941 \\
\pm 402\end{array}$ \\
\hline$B^{6}{ }_{0}$ & --- & --- & $\begin{array}{l}152 \pm \\
4\end{array}$ & $\begin{array}{l}126 \pm \\
46\end{array}$ & --- \\
\hline$B_{4}^{6}$ & --- & --- & $\begin{array}{l}2770 \pm \\
4\end{array}$ & $\begin{array}{l}1464 \\
\pm 63\end{array}$ & --- \\
\hline$g_{\text {eff }}$ & --- & $\begin{array}{l}1.99 \pm \\
0.01\end{array}$ & --- & --- & --- \\
\hline$z J^{\prime}$ & $\begin{array}{l}-0.09 \\
\pm 0.01\end{array}$ & --- & --- & --- & --- \\
\hline$J$ & --- & $\begin{array}{l}+2.4 \pm \\
0.6\end{array}$ & $\begin{array}{l}+4.2 \pm \\
1.5\end{array}$ & $\begin{array}{l}+2.2 \pm \\
1.0\end{array}$ & $\begin{array}{l}-0.14 \pm \\
0.09\end{array}$ \\
\hline SQ & $1.2 \%$ & $0.7 \%$ & $0.5 \%$ & $0.3 \%$ & $0.3 \%$ \\
\hline
\end{tabular}

In a next step, we model the data of compound $\mathbf{1}$ to estimate the strength and magnitude of the exchange interaction between the $\mathrm{Cu}^{2+}$ center and the $\mathrm{Ln}^{3+}$ centers of 1-3. Due to the well isolated orbital singlet ground state ${ }^{8} A_{1}$ of $\mathrm{Gd}^{3+}$ centers, the $\mathrm{Gd}^{3+}$ center of $\mathbf{1}$ was modeled as an isotropic spin center with effective spin $S_{\text {eff }}=7 / 2$ and geff $_{\text {slight- }}$ ly less than the $g$ factor of the free electron due to mixing of excited states into the ground state. The found exchange interaction parameter of $+2.4 \mathrm{~cm}^{-1}$ indicates ferromagnetic exchange interactions between the $\mathrm{Cu}^{2+}$ center and the $\mathrm{Gd}^{3+}$ center, i.e. in the typical range for $3 \mathrm{~d}-4 \mathrm{f}$ exchange interactions. ${ }^{33}$ We employed the same strategy for the fitting procedure of the parameters of 2 and 3: Similar to 4 , the starting values of the ligand field parameters were generated by the PCEM assuming a ligand field of approximately $C_{4 v}$ symmetry (in this case representing a capped square antiprism). The relations $\mathrm{B}_{4}^{4} / \mathrm{B}^{4}$ ond $\mathrm{B}_{4}^{6} / \mathrm{B}^{6}{ }_{0}$ were initially kept constant, and - after no further improvement of SQ - were allowed to vary while retaining the sign of the parameters. The starting value for the exchange coupling was set to the value of $J$ as estimated for 1 . While the full basis of a $4 \mathrm{f}^{\mathrm{N}}$ electron configuration was used for the calculation of the single ion effects $(2(N=8): 3003$ states and 3 $(N=9): 2002$ states, respectively), this basis was reduced to the $2 J+1$ states $(2: 13,3: 16)$ of the ground multiplet in addition to the 10 states of the $\mathrm{Cu}^{2+}$ center when considering the exchange interactions. The values of $B^{k}$ and $J$ of the corresponding least-squares fits are shown in Table 1. The ligand field parameters describe the $\mathrm{Tb}^{3+}$ center or the $\mathrm{Dy}^{3+}$ center, respectively, as a distorted capped square antiprism. The exchange interactions are ferromagnetic, and of same magnitude $\left(\sim 2-3 \mathrm{~cm}^{-1}\right)$ within the error margins.

The magnetic data of 5 are shown as $\chi_{\mathrm{m}} T$ vs. $T$ curve at $0.1 \mathrm{~T}$ and $M_{\mathrm{m}}$ vs. $B$ curve at $2.0 \mathrm{~K}$ in Figure 4 . The $\chi_{\mathrm{m}} T$ value of $0.84 \mathrm{~cm}^{3} \mathrm{~K} \mathrm{~mol}^{-1}$ at $290 \mathrm{~K}$ is within the expected range ${ }^{28}$ of $0.72-1.21 \mathrm{~cm}^{3} \mathrm{~K} \mathrm{~mol}^{-1}$ for two non-interacting $\mathrm{Cu}^{2+}$ centers. By decreasing temperature, $\chi_{\mathrm{m}} T$ slightly decreases to $0.82 \mathrm{~cm}^{3} \mathrm{~K} \mathrm{~mol}^{-1}$ at $18.0 \mathrm{~K}$, and subsequently drops down to $0.78 \mathrm{~cm}^{3} \mathrm{~K} \mathrm{~mol}^{-1}$ at $2.0 \mathrm{~K}$. This drop is potentially due to very weak antiferromagnetic exchange interactions between the two $\mathrm{Cu}^{2+}$ centers. The molar magnetization at $2.0 \mathrm{~K}$ continuously grows by increasing the applied magnetic field B. At 5.0 T, $M_{\mathrm{m}}$ is $2.0 \mathrm{~N}_{\mathrm{A}} \mu_{\mathrm{B}}$ and not saturated.

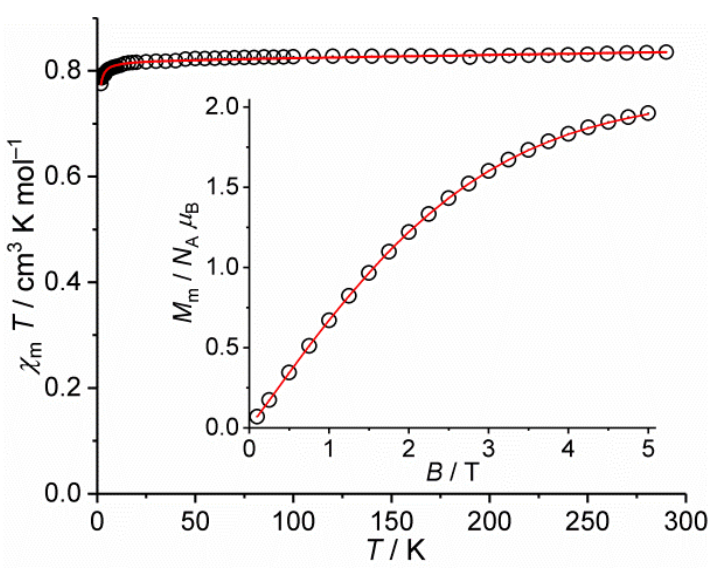


Figure 4. Temperature dependence of $\chi_{\mathrm{m}} T$ at $0.1 \mathrm{~T}$, and field dependence of the molar magnetization $M_{m}$ at $2.0 \mathrm{~K}$ (inset) of 5; open symbols: experimental data; solid red lines: least-squares fits.

To model the data of $\mathbf{5}$ using CONDON, we assume both $\mathrm{Cu}^{2+}$ centers to be identical, in line with the molecular structure. The geometry of the ligand field of both centers is approximated as a tetragonal distorted tetrahedron $\left(D_{2 \mathrm{~d}}\right)$. Starting values of the ligand field parameters were calculated by applying the PCEM, and all 10 states of the $3 \mathrm{~d}^{9}$ electron configuration were considered per center during the fitting procedure. The result of the least-squares fit of quality $\mathrm{SQ}=0.3 \%$ are given in Table 1 . The two $\mathrm{Cu}^{2+}$ centers exhibit ligand field parameters that describe a tetragonal strongly distorted tetrahedral or almost quadratic planar coordination of the central ion. The exchange coupling constant is very small, representing an antiferromagnetic exchange interaction. The small magnitude of $J$ is consistent with the large distance between both $\mathrm{Cu}^{2+}$ ions (6.813 $\AA$ ).

FT-IR and FT-IRRAS Spectra. HL.SMe was first immobilized in the form of self-assembled monolayers (SAMs) on an Au surface from a $1.0 \mathrm{mmol}$ ethanolic solution to assess the structural integrity of the uncoordinated, charge-neutral ligand on the solid substrate. As the comparison of the FTIR and FT-IRRAS spectra of HL-SMe (see Supporting Information) indicates that its chemical structure remains effectively unchanged upon adsorption, ${ }^{34}$ we subjected complexes 1-4 to IRRAS analysis. Although a small shift of the recorded IR vibrational bands is observed due to the presence of different $\mathrm{Ln}^{3+}$ ions in the respective compounds and thereby the resulting change in bond strengths, which is directly linked to the vibration frequency, the FT-IR spectra of 1-4 are nearly identical, as expected for these quasiisostructural complexes (see Supporting Information). Therefore, we here discuss as a typical example only the results of FT-IRRAS measurements of the Tb-containing sample (2). As can be seen in Figure 5, the similarity of the vibration frequencies of the recorded FT-IR and FT-IRRAS peaks in the fingerprint region, which arise mainly due to $=\mathrm{C}-\mathrm{H}$ in- and out-of-plane deformation as well as $\mathrm{C}=\mathrm{C}$ stretching vibrations of the aryl rings, suggests an intact immobilization of complex 2 on the Au surface. Due to the surprisingly high quality of the first-measured FT-IRRAS spectrum (denoted as "IRRAS 1" in Figure 5) and the small amount of solvent used for washing the Au substrate dropwise, we assume to have a thin layer of compound $\mathbf{2}$ on the gold surface. Subsequently, this Au substrate was dipped into methanol to wash the surface more carefully and a second FT-IRRAS spectrum ("IRRAS 2" in Figure 5) was recorded. The intensity of the obtained peaks decreases (as expected) and the remaining signals indicate that compound $\mathbf{2}$ still forms an intact thin layer on the substrate - presumably a monolayer. The insignificant difference in the wavenumbers of the peaks in the FT-IR and FT-IRRAS spectra of $\mathbf{2}$ (Table 2) is associated with the different sample forms ( $\mathrm{KBr}$ vs. Au substrate) and the applied measurement methods (through-beam vs. reflective). ${ }^{35}$



Figure 5. IRRAS 1 (red), IRRAS 2 (black) and IR (blue) spectra of compound 2 in the $1800-1000 \mathrm{~cm}^{-1}$ region.

Table 2. A comparison of selected band vibrations between bulk IR (as KBr pellet) and IRRAS (on gold substrate) spectra of compound $\mathbf{2}^{36}$

\begin{tabular}{llll}
\hline IR & IRRAS 1 & IRRAS 2 & assignment \\
$\tilde{V} / \mathrm{cm}^{-1}$ & $\tilde{V} / \mathrm{cm}^{-1}$ & $\tilde{V} / \mathrm{cm}^{-1}$ & \\
\hline 3062 & 3017 & 3007 & $\tilde{V}_{\mathrm{ar}}(\mathrm{C}-\mathrm{H})$ \\
1612 & 1609 & 1612 & $\tilde{V}_{\mathrm{ar}}(\mathrm{C}=\mathrm{C})$ \\
1560 & $1560-1542$ & $1553-1547$ & $\tilde{V}_{\mathrm{as}}\left(\mathrm{COO}^{-}\right)$ \\
$1489-1381$ & 1489 & & $\tilde{V}_{\mathrm{s}}\left(\mathrm{COO}^{-}\right)$ \\
$1463-1381$ & $1467-1447$ & $1463-1442$ & $\tilde{V}_{\mathrm{ar}}(\mathrm{C}=\mathrm{C})$ \\
1381 and & 1383 and 1332 & 1391 and 1382 & $\tilde{V}_{\mathrm{s}}(\mathrm{COO})$ \\
1298 & 1243 & 1239 & $\delta_{\mathrm{ip}}(=\mathrm{C}-\mathrm{H})$ \\
1237 & 1195 & 1192 & $\delta_{\mathrm{ip}}(=\mathrm{C}-\mathrm{H})$ \\
$1198-1184$ & $1109-1080$ & 1106 & $\delta_{\mathrm{ip}}(=\mathrm{C}-\mathrm{H})$ \\
1094 and & & & \\
1078 & & & \\
\hline
\end{tabular}

Large-Area Charge Transport Measurements. In conjunction with the IRRAS results, we further investigated the propensity of compounds 1-4 to form SAMs on a gold substrate as bottom electrode and thereby of molecular tunneling junctions by employing eutectic Ga-In (EGaln) as top electrode. ${ }^{10} \mathrm{EGaln}$ has proven to be instrumental in characterizing large-area junctions comprising a wide variety of SAMs. It is able to distinguish between details of the orientation of terminal methyl groups in alkanethiols, ${ }^{37}$ resolve conformation-driven quantum interference in aromatic $\mathrm{SAMs}^{13}$ and help determine the orientation of SAMs of proteins. ${ }^{38}$

We succeeded in growing SAMs of the target compounds by immersing freshly cleaved template-stripped gold substrates (atomically smooth $\mathrm{Au}^{\top S}$ ) 39 in a $\sim 0.1 \mathrm{mM}$ methanolic solution of each metal complex overnight (see Supporting Information for details). After rinsing with pure methanol and drying in a gentle stream of nitrogen, the SAMs were contacted with EGaln tips to form junctions of the structure $\mathrm{Au}^{\mathrm{TS}} / / \mathrm{SAM} / / \mathrm{Ga}_{2} \mathrm{O}_{3} / \mathrm{EGaln}$ where "/" denotes interface defined by chemisorption and "//" by physisorption. Note that 
EGaln is an eutectic alloy of $\mathrm{Ga}$ and $\ln (75.5 \% \mathrm{Ga}$ and $24.5 \% \mathrm{In}$ by weight), the surface of which is covered by thin, conductive, self-limiting layer of $\mathrm{Ca}_{2} \mathrm{O}_{3}{ }^{40}$ Along with EGaln we used ellipsometry and STM measurements to characterize the SAMs (see Supporting Information for details). Although we observe the formation of a monolayer of complexes, this type of self-assembly should not be confused with the densely-packed, upright SAMs of thiolates that form from, for example, alkanethiols. The characterization that we provide (e.g., ellipsometry and FT-IRRAS) only shows that the complexes are immobilized on the surface in a disordered monolayer. They lay flat, not upright, and are rotated randomly about the surface-normal axis and the identity of the complex does not substantially alter the structure of the monolayer.

Finally, we performed an analysis of the current-voltage (I$v)$ characteristics of the engineered SAMs. The results of our I-V measurements are illustrated in Figure 6. Apart from minor differences in the shape of $J-V$ curves (current density $J=I / S$, where $S$ is the area of the junction) the four SAMs are indistinguishable. By replotting $\mathrm{J}-\mathrm{V}$ data in FowlerNordheim coordinates (transition voltage spectroscopy ${ }^{41}$ ) it is possible to obtain information about energy level alignment inside the junction. All values of transition voltages $\left(V_{T}\right)$ coalesce to $\sim 0.3 \mathrm{~V}$ (see Supporting Information). This value can be attributed to the $\beta d_{x-y}^{2}{ }^{2}$ main transmission channel of $\mathrm{Cu}$, which lies close to the Fermi level and is shared by all compounds 1-4 (see DFT section below for details). A similar value of $V_{T}$ was previously ascribed to $\mathrm{Ga}_{2} \mathrm{O}_{3}$ in junctions comprising SAMs of alkanethiolates; ${ }^{42}$ however, the frontier orbitals of the alkane backbone are much higher in energy than $\mathrm{Ga}_{2} \mathrm{O}_{3}$, which is not the case for the complexes in this study. Moreover, the transition voltages for SAMs with accessible frontier orbitals have been unambiguously assigned in EGaln junctions ${ }^{43}$ and the value of $\sim 0.3 \mathrm{~V}$ is likely a numerical coincidence. Assigning the transition voltage to the $\beta \mathrm{dx}_{x-y}^{2}{ }^{2}$ main transmission channel of $\mathrm{Cu}$ is also consistent with a single-level model that was proposed for ferrocene-containing molecules in which the Fe center mediates transport. ${ }^{44}$



Figure 6. Plots of the logarithmic current density versus applied potential for SAMs of the compounds 1-4. Values of $\log |J|$ at $V=0$ $\checkmark$ are omitted for clarity. Error bars represent the standard devia- tion of Gaussian fits. Four traces are indistinguishable at full bias range.

Most SAMs studied previously by EGaln are chemically bound to the substrate (usually by sulfur-metal bonds). However, in compounds 1-4 the sulfur atoms are divalent (thioether) and can only weakly interact with the metal surface through physisorption. ${ }^{45-47}$ Thus we expect i) the SAM to be poorly ordered and ii) the molecules to be weakly coupled to the bottom electrode, that is to exhibit high resistance. Due to the absence of a free thiol group to bind to the bottom substrate it was not clear whether these complexes will form a SAM and if so, whether it is possible to measure them in large-area junctions. However, all compounds 1-4 formed surprisingly electrically robust monolayers with the average yield of working EGaln junctions of $67 \%$. This observation may seem counter-intuitive; however, there is evidence that disordered, liquid-like SAMs yield better data, because molecular motion is much faster than the time scale of the measurement. ${ }^{48}$ We are not suggesting that the complexes are liquid-like, only that the degree of order in a SAM is not positively correlated to the quality of the data obtained from large-area junctions measured using EGaln.



Fig. XX $\beta$-plot for the series of alkanethiolates on $\mathrm{Ag}^{\mathrm{TS}}$ with the $J_{\text {avg }}$ of compounds 1-4. Length for alkanethiolates is the SulphurHydrogen distance measured from $\mathrm{MM}_{2}$ minimized structure. Length $a$ corresponds to the shortest dimension of the complexes measured from the crystal structures and length $b$ corresponds to the longest, length $c$ corresponds to the average ellipsometric thickness.

To assess the conductivity of compounds 1-4 we determined the average conductance of the combined data and compared it to the benchmark system for the SAM-based large-area molecular junctions - alkanethiolates on Ag (see Supporting Information). It was previously shown that SAMs of even-numbered alkanethiols on $\mathrm{Ag}^{\mathrm{TS}}$ and $\mathrm{Au}^{\mathrm{TS}}$ exhibit identical transport properties in EGaln junctions, ${ }^{49}$ which allows the comparison of the data across the substrates. To estimate the thickness of the monolayers we performed ellipsometric measurements on the monolayers and used crystal structures of the complexes. The data are consistent with the thickness of $\sim 1.3 \mathrm{~nm}$. As expected, due to the higher contact resistance at the bottom interface, 
the average conductivity of our SAMs is lower ( $\sim 2-3$ orders of magnitude) than that for alkanethiolates of equivalent length.

DFT Study of Transport Properties. To obtain a better understanding of the collected current-voltage data showing the similar conductivity behavior for all studied SAMs, we performed quantum mechanical calculations. However, the DFT combined with equilibrium Green function (EGF) was employed to calculate the coherent transport properties of only complexes 1 and $\mathbf{4}$. The reason for this is the singledeterminant nature of the DFT, which limits the description of the f-type ions because of their degenerated ground state..$^{50}$ Although some information about the electronic structure of the f-type ions can indeed be extracted from DFT calculations, we have restricted our calculations to the non-degenerated ground-state ions $\mathrm{Gd}^{\mathrm{III}}$ and $\mathrm{Y}^{\mathrm{III}}$.

To the best of our knowledge, no X-ray structure to build up the EGaln electrode is available. Nonetheless, for this kind of Metal-SAM-EGaln junctions it has been shown that the SAM and not the electrodes dominates the charge transport..$^{40}$ Due to this fact, the molecular structure of $\mathbf{1}$ and 4 as determined by single-crystal $\mathrm{X}$-ray diffraction was embedded between two Au(111) electrodes as shown in Figure 7 , thus simulating the experimental two-terminal setup. As the interaction between neighboring molecules is weak according to our experimental data, a single molecule approach is hence well suited to calculate the transmission spectra.

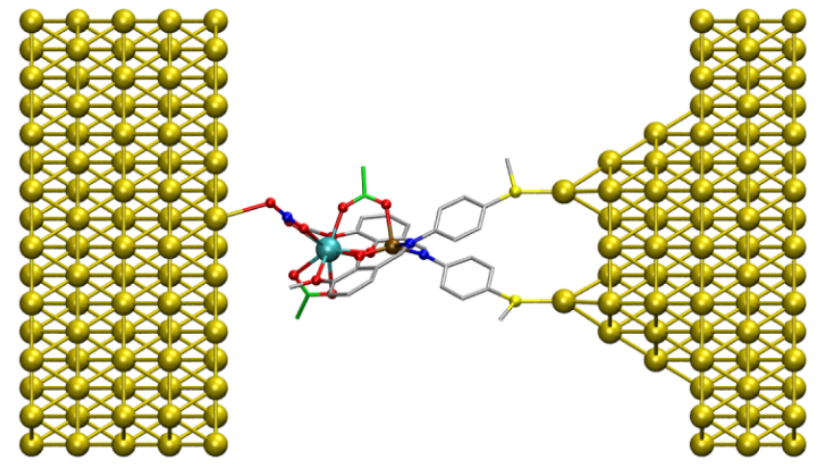

Figure 7. A theoretical setup to examine transport properties of compounds 1 and 4 . The explicit asymmetry in the gold electrodes definition was introduced to avoid overlapping between neighboring atoms. Color code: $\mathrm{C}$ of L·SMe ${ }^{-}$: gray, $\mathrm{C}$ of acetate: green, $\mathrm{Cu}$ brown, Gd/Y: turquoise, N: blue, O: red, S: yellow.

The electronic structure calculation of 1 suggests a ferromagnetic ground state interaction between the $\mathrm{Cu}$ and $\mathrm{Gd}$ magnetic centers, in agreement with the experimental data. The transmission spectra $(T(E))$ of $\mathbf{1}$ and $\mathbf{4}$ and their projected density of states (PDOS) on the molecule are shown in Figures 8 and 9, respectively.
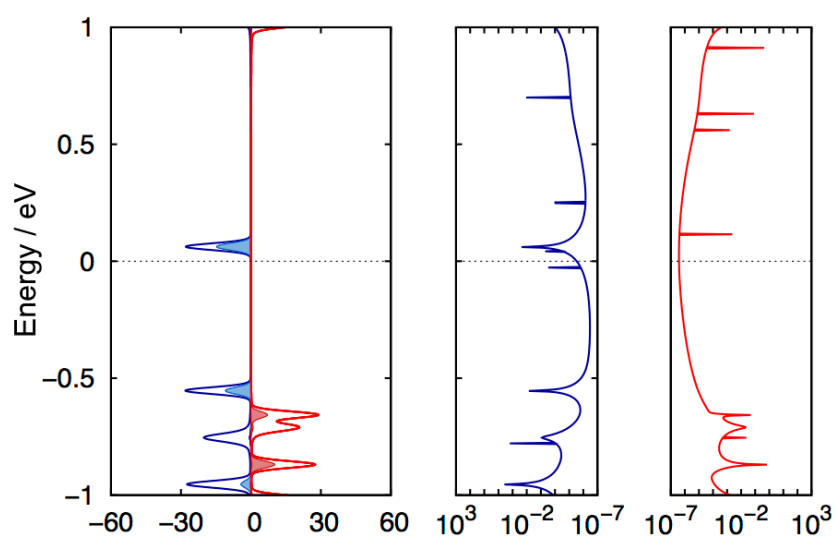

Figure 8. PDOS on the molecule (left) and transmission spectrum $\log (T(E))$ of $\mathbf{1}$ (right). The Fermi energy is set to zero. Red and blue colors stand for $\alpha$ and $\beta$ spin orbital contributions. The shaded peaks correspond to the $\mathrm{Cu}$ atom contribution to the molecular orbital. Gd has almost no contribution around the Fermi level.

The PDOS of complex $\mathbf{1}$ (Fig. 8, left) shows a single peak at $0.1 \mathrm{eV}$ above the Fermi level $\left(E-E_{\mathrm{F}}=0\right)$ that corresponds to a molecular level with a high contribution of the $\beta d_{x} 2-y^{2}$ atomic orbital of the $\mathrm{Cu}$ center. As can be seen in the transmission spectrum (Fig. 8, right), this molecular spin orbital has its corresponding transmission peak. Because of its proximity to the Fermi level, this energy level constitutes the main transmission channel in the junction. Complex 4 presents a very similar behavior as illustrated in Figure 9. We note again that $\mathrm{Cu}$ atom has a strong contribution to the transmission near the Fermi level as in the \{CuGd\} analogue and the distance to the Fermi level is the same. Moreover, both the PDOS and the transmission are almost identical for both cases for the shown energy range. Thus, the transmission spectra are to a large extent fully independent on the lanthanide atom for a large energy range. This is in excellent agreement with the indistinguishable $I-V$ curves obtained for complexes 1-3 ( $\mathrm{Ln}=\mathrm{Gd}, \mathrm{Tb}, \mathrm{Dy})$ and 4 $(L n=Y)$. Because of the $\beta$-polarized transmission, we expect to observe spin-filtering properties for all set of the studied metal complexes upon their future contact with a magnetic electrode.


Figure 9. PDOS on the molecule (left) and transmission spectrum $\log (T(E))$ of 4 (right). The Fermi energy is set to zero. Red and blue colors represent $\alpha$ and $\beta$ spin orbital contributions. The shaded 
peaks correspond to the $\mathrm{Cu}$ atom contribution to the molecular orbital. $Y$ has almost no contribution around the Fermi level.

\section{CONCLUSIONS}

We have demonstrated that the charge-neutral $3 \mathrm{~d}-4 \mathrm{f}$ complexes in 1-4, exhibiting air, moisture and thermal stability, serve as a suitable materials platform for the study of largearea molecular transport properties. Although we cannot unequivocally rule out the possibility of multilayer formation based on our IRRAS experiments, the acquired STM and ellipsometry data point to densely packed, disordered monolayers of the $\left\{\mathrm{CU}^{\prime \prime} \mathrm{Ln}^{\prime \prime \prime}\right\}$ title complexes. Remarkably, varying the lanthanide ion from $\mathrm{Cd}^{3+}(1)$ to $\mathrm{Tb}^{3+}(2)$ and $\mathrm{Dy}^{3+}$ (3) does not have a measurable effect on the conductivity of these SAMs in $\mathrm{Au}^{\mathrm{TS}} / / \mathrm{SAM} / / \mathrm{Ga}_{2} \mathrm{O}_{3} /$ EGaln junctions, most likely due to the fact that their $4 \mathrm{f}$ states are too deep in energy. We conjecture that only early lanthanides, with their $4 \mathrm{f}$ states close to the Fermi edge, would be able to significantly affect the molecular charge transport..$^{51}$ The structural constraints of the present ligand system, however, preclude the integration of such larger early lanthanide ions. Our DFT+EGF calculations indicate that the tunneling transport should occur through the molecular spin orbital of the copper center forming the main transmission channel across the molecular junction. The results obtained open up far-reaching opportunities for investigation of this type of molecular structures toward their binuclear $3 \mathrm{~d}-4 \mathrm{f}$ congeners by changing $\mathrm{Cu}$ for another $3 \mathrm{~d}$-metal spin center. Such a modification of the transition metal ion may have substantial effects on the electronic and magnetic picture of the molecule, thus influencing conductivity and potential spin-filtering behavior when applying a magnetic electrode.

\section{EXPERIMENTAL AND COMPUTATIONAL METHODS}

Materials and methods. The syntheses of the Schiff base ligand $\mathrm{HL} \cdot \mathrm{SMe}$ and compounds $\mathbf{1 - 6}$ were carried out under aerobic conditions. All commercial starting materials were used as received. Solvents were used without further purification. $\mathrm{CHN}$ analysis was performed using a Vario EL elemental analyzer. IR spectra of $\mathrm{HL} \cdot \mathrm{SMe}$ and 1-6 were recorded on a Nicolet Avatar $360 \mathrm{FTIR}$ spectrometer ( $\mathrm{KBr}$ pellets, $m_{\mathrm{KBr}} \approx 250 \mathrm{mg}$ ) in the range $\tilde{v}=4000-400 \mathrm{~cm}^{-1}$. TGA curves for $\mathrm{HL} \cdot \mathrm{SMe}$ and $\mathbf{1}-\mathbf{5}$ were obtained in air and under a nitrogen atmosphere with a heating rate of $5 \mathrm{~K} \mathrm{~min}^{-1}$ in the temperature range $25-800{ }^{\circ} \mathrm{C}$ by using a Mettler Toledo TGA/SDTA 851e instrument. The ESI-MS spectra of $\mathrm{HL} \cdot \mathrm{SMe}$ and 1-6 in the positive ion mode were recorded on a 4000 QTRAP mass spectrometer system by using the LC/LC-MS method with direct infusion.

Synthesis of the Schiff base (HL-SMe). 2-Hydroxy-3methoxybenzaldehyde (ortho-Vanillin) ( $3.738 \mathrm{~g}, 24.6 \mathrm{mmol}$ ) was dissolved in $100 \mathrm{~mL}$ of ethanol. 4-(methylthio)aniline (3.0 $\mathrm{mL}, 24.6 \mathrm{mmol}$ ) was added to the yellow solution, resulting in a color change to orange. The solution was acidified with 5 drops of acetic acid, to catalyze the reaction. After stirring under refluxing conditions for 5 hours the ethanolic solution was cooled down to room temperature and stored in a flask under ambient conditions. Orange needle-like crystals of HL-SMe were isolated after one day and washed with ice cooled ethanol and pentane. Yield of the air-dried crystals: $6.253 \mathrm{~g}(87.2 \%)$. Elemental analysis, calcd. for $\mathrm{C}_{15} \mathrm{H}_{15} \mathrm{NO}_{2} \mathrm{~S} \cdot 0.1$ pentane $\left(\mathrm{M}=273.35 \mathrm{~g} \cdot \mathrm{mol}^{-1}\right.$ without crystal solvent): C, 66.35; H, 5.82 and N, $4.99 \%$. Found: C, 66.61; H, 5.66 and N, 5.15\%. IR (KBr pellet), $\tilde{v}_{\max } / \mathrm{cm}^{-1}: 3442$ (m, br), $3000(\mathrm{vw}), 2955(\mathrm{w}), 2921(\mathrm{w}), 2832(\mathrm{vw}), 1883(\mathrm{vw})$, 1745 (vw), $1609(\mathrm{~s}), 1571(\mathrm{~m}), 1561(\mathrm{sh}), 1466(\mathrm{~s}), 1439(\mathrm{~m})$, 1405 (sh), $1361(\mathrm{~m}), 1326(\mathrm{sh}), 1271(\mathrm{sh}), 1257(\mathrm{~s}), 1199(\mathrm{~m})$, $1180(\mathrm{w}), 1123(\mathrm{w}), 1091(\mathrm{~m}), 1077(\mathrm{~m}), 1008(\mathrm{w}), 968(\mathrm{~s}), 936$ $(\mathrm{m}), 861(\mathrm{~m}), 833(\mathrm{w}), 821(\mathrm{~s}), 812(\mathrm{sh}), 778(\mathrm{~m}), 732(\mathrm{~s}), 708$ (sh), $679(\mathrm{w}), 582(\mathrm{w}), 547(\mathrm{w}), 503(\mathrm{~m}), 421(\mathrm{w})$. MS (MeOH, ESI): $\mathrm{m} / \mathrm{z}=296.071\left(\mathrm{NaC}_{15} \mathrm{H}_{15} \mathrm{NO}_{2} \mathrm{~S}^{+}, 100 \%\right), 274.089$ $\left(\mathrm{HC}_{15} \mathrm{H}_{15} \mathrm{NO}_{2} \mathrm{~S}^{+}, 40 \%\right.$ ). ${ }^{1} \mathrm{H}-\mathrm{NMR}$ (in $\mathrm{CD}_{2} \mathrm{Cl}_{2}, 400 \mathrm{MHz}$ ): $\delta=13.43$ (s, $1 \mathrm{H}, \mathrm{OH}), 8.66(\mathrm{~s}, 1 \mathrm{H}, \mathrm{N}=\mathrm{CH}-\mathrm{ar}), 7.33-7.26(\mathrm{~m}, 4 \mathrm{H}, \mathrm{H}-\mathrm{ar})$, 7.04 (dd, $1 \mathrm{H}, \mathrm{H}$-ar), 7.00 (dd, $1 \mathrm{H}, \mathrm{H}$-ar), 6.89 (t, 1H, H-ar), $3.90\left(\mathrm{~s}, 3 \mathrm{H}, \mathrm{H}_{3} \mathrm{C}-\mathrm{O}-\mathrm{R}\right)$ and $2.51\left(\mathrm{~s}, 3 \mathrm{H}, \mathrm{H}_{3} \mathrm{C}-\mathrm{S}-\mathrm{R}\right) .{ }^{13} \mathrm{C}-\mathrm{NMR}$ (in $\left.\mathrm{CD}_{2} \mathrm{Cl}_{2}, 100 \mathrm{MHz}\right): \delta=162.6,151.9,149.0,145.8,138.2,127.8$, $124.3,122.2,119.8,119.0,115.5,56.7$ and $16.3 \mathrm{ppm}$.

Synthesis of $\left[\mathrm{CuGd}(\mathrm{L} \cdot \mathrm{SMe})_{2}(\mathrm{OOCMe})_{2}\left(\mathrm{NO}_{3}\right)\right] \cdot \mathrm{MeOH}(1)$. The Schiff base $\mathrm{HL} \cdot \mathrm{SMe}(0.137 \mathrm{~g}, 0.5 \mathrm{mmol})$ was dissolved in 10 $\mathrm{mL}$ of methanol, and triethylamine $(0.08 \mathrm{~mL}, 0.58 \mathrm{mmol})$ was introduced into the solution. $\mathrm{Gd}\left(\mathrm{NO}_{3}\right)_{3} \cdot 6 \mathrm{H}_{2} \mathrm{O}(0.113 \mathrm{~g}$, $0.25 \mathrm{mmol}$ ) was added and the reaction mixture was refluxed for 15 minutes to give a clear orange solution. $\left[\mathrm{Cu}_{2}(\mathrm{OOCMe})_{4}\left(\mathrm{H}_{2} \mathrm{O}\right)_{2}\right](0.050 \mathrm{~g}, 0.13 \mathrm{mmol})$ was then added, which resulted in a color change to dark brown. The methanolic solution was refluxed for 1 hour, filtered off and the filtrate was stored in a capped vial at room temperature. Dark brown single crystals of compound $\mathbf{1}$ were isolated after one day and washed with a small amount of ice cold methanol. Yield of the air-dried crystals: $0.074 \mathrm{~g}(31.3 \%)$. Elemental analysis, calcd. for $\mathrm{C}_{34} \mathrm{Cu}_{1} \mathrm{H}_{34} \mathrm{Gd}_{1} \mathrm{~N}_{3} \mathrm{O}_{11} \mathrm{~S}_{2}$ ( $\mathrm{M}=$ $945.57 \mathrm{~g} \cdot \mathrm{mol}^{-1}$ without crystal solvent): $\mathrm{C}, 43.19 ; \mathrm{H}, 3.62$ and $\mathrm{N}, 4.44 \%$. Found: $\mathrm{C}, 42.88 ; \mathrm{H}, 3.50$ and N, $4.59 \%$. IR $(\mathrm{KBr}$ pellet), $\tilde{v}_{\max } / \mathrm{cm}^{-1}: 3442(\mathrm{~m}, \mathrm{br}), 3062(\mathrm{w}), 2984(\mathrm{w}), 2919$ (w), 2842 (w), 1612 (vs), 1560 (s), 1465 (vs), 1411 (s), 1381 (m), $1340(\mathrm{w}), 1298(\mathrm{~s}), 1237(\mathrm{~s}), 1198(\mathrm{~s}), 1184(\mathrm{~m}), 1094(\mathrm{~m}), 1078$ $(\mathrm{m}), 1048(\mathrm{w}), 1032(\mathrm{w}), 1013(\mathrm{w}), 969(\mathrm{~m}), 931(\mathrm{w}), 853(\mathrm{~m})$, $824(\mathrm{~m}), 789(\mathrm{w}), 735(\mathrm{~m}), 712(\mathrm{w}), 678(\mathrm{~m}), 652(\mathrm{w}), 612$ $(\mathrm{w}), 584(\mathrm{~m}), 540(\mathrm{w}), 446(\mathrm{w})$. MS (MeCN, ESI): $\mathrm{m} / \mathrm{z}=$ $630.068\left(\mathrm{C}_{30} \mathrm{Cu}_{1} \mathrm{H}_{28} \mathrm{Na}_{1} \mathrm{~N}_{2} \mathrm{O}_{4} \mathrm{~S}_{2}{ }^{+}, 15 \% ; \quad\left[\mathrm{CuNa}(\mathrm{L} \cdot \mathrm{SMe})_{2}\right]^{+}\right)$, $883.031 \quad\left(\mathrm{C}_{34} \mathrm{Cu}_{1} \mathrm{H}_{34} \mathrm{Cd}_{1} \mathrm{~N}_{2} \mathrm{O}_{8} \mathrm{~S}_{2}{ }^{+}, \quad 69 \%\right.$ [CuGd(L-SMe $\left.\left.)_{2}(\mathrm{OOCMe})_{2}\right]^{+}\right), 944.083\left(\mathrm{C}_{45} \mathrm{Cu}_{2} \mathrm{H}_{42} \mathrm{~N}_{3} \mathrm{O}_{6} \mathrm{~S}_{3}{ }^{+}, 14\right.$ \%; $\left.\left[\mathrm{Cu}_{2}(\mathrm{~L} \cdot \mathrm{SMe})_{3}\right]^{+}\right), 1096.093\left(\mathrm{C}_{47} \mathrm{Cu}_{1} \mathrm{H}_{45} \mathrm{Cd}_{1} \mathrm{~N}_{3} \mathrm{O}_{8} \mathrm{~S}_{3}{ }^{+}, 100 \%\right.$; $\left.\left[\mathrm{CuGd}(\mathrm{L} \cdot \mathrm{SMe})_{3}(\mathrm{OOCMe})\right]^{+}\right)$.

Synthesis of $\left[\mathrm{CuTb}(\mathrm{L} \cdot \mathrm{SMe})_{2}(\mathrm{OOCMe})_{2}\left(\mathrm{NO}_{3}\right)\right] \cdot \mathrm{MeOH}$ (2). Compound 2 was synthesized following the procedure described for compound 1, replacing $\mathrm{Gd}\left(\mathrm{NO}_{3}\right)_{3} \cdot 6 \mathrm{H}_{2} \mathrm{O}$ by $\mathrm{Tb}\left(\mathrm{NO}_{3}\right)_{3} \cdot 6 \mathrm{H}_{2} \mathrm{O}(0.114 \mathrm{~g}, 0.25 \mathrm{mmol})$. Yield of the air-dried crystals: $0.161 \mathrm{~g}(68.0 \%)$. Elemental analysis, calcd. for $\mathrm{C}_{34} \mathrm{Cu}_{1} \mathrm{H}_{34} \mathrm{~Tb}_{1} \mathrm{~N}_{3} \mathrm{O}_{11} \mathrm{~S}_{2} \cdot \mathrm{H}_{2} \mathrm{O}\left(\mathrm{M}=947.25 \mathrm{~g} \cdot \mathrm{mol}^{-1}\right.$ without crystal solvent): $\mathrm{C}, 42.31 ; \mathrm{H}, 3.76$ and $\mathrm{N}, 4.35 \%$. Found: $\mathrm{C}, 42.33 ; \mathrm{H}$, 3.53 and N, $4.28 \%$. IR (KBr pellet), $\tilde{v}_{\max } / \mathrm{cm}^{-1}: 3442(\mathrm{~m}, \mathrm{br})$, 3062 (w), 2983 (w), 2919 (w), 2842 (w), 1612 (vs), 1560 (s), 1489 (s), 1464 (vs), 1411 (s), 1381 (m), 1298 (s), 1237 (s), 1198 (s), $1184(\mathrm{~m}), 1094(\mathrm{~m}), 1078(\mathrm{~m}), 1032(\mathrm{w}), 1010(\mathrm{w}), 969$ $(\mathrm{m}), 931(\mathrm{w}), 853(\mathrm{~m}), 824(\mathrm{~m}), 734(\mathrm{~m}), 711(\mathrm{w}), 679(\mathrm{~m})$, $652(w), 612(w), 583(m), 539(w), 447(w) . M S$ (MeCN, ESI): 
$\mathrm{m} / \mathrm{z}=630.068 \quad\left(\mathrm{C}_{30} \mathrm{Cu}_{1} \mathrm{H}_{28} \mathrm{Na}_{1} \mathrm{~N}_{2} \mathrm{O}_{4} \mathrm{~S}_{2}{ }^{+}, \quad 100 \%\right.$; $\quad$ Cu$\left.\left.\mathrm{Na}(\mathrm{L} \cdot \mathrm{SMe})_{2}\right]^{+}\right), \quad 884.031 \quad\left(\mathrm{C}_{34} \mathrm{Cu}_{1} \mathrm{H}_{34} \mathrm{~Tb}_{1} \mathrm{~N}_{2} \mathrm{O}_{8} \mathrm{~S}_{2}{ }^{+}, \quad 100 \%\right.$; $\left.\left[\mathrm{CuTb}(\mathrm{L} \cdot \mathrm{SMe})_{2}(\mathrm{OOCMe})_{2}\right]^{+}\right), 944.081\left(\mathrm{C}_{45} \mathrm{Cu}_{2} \mathrm{H}_{42} \mathrm{~N}_{3} \mathrm{O}_{6} \mathrm{~S}_{3}{ }^{+}, 40\right.$ \%; $\left.\left[\mathrm{Cu}_{2}(\mathrm{~L} \cdot \mathrm{SMe})_{3}\right]^{+}\right), 1097.092\left(\mathrm{C}_{47} \mathrm{Cu}_{1} \mathrm{H}_{45} \mathrm{~Tb}_{1} \mathrm{~N}_{3} \mathrm{O}_{8} \mathrm{~S}_{3}{ }^{+}, 65 \%\right.$; $\left.\left[\mathrm{CuTb}(\mathrm{L} \cdot \mathrm{SMe})_{3}(\mathrm{OOCMe})\right]^{+}\right)$.

Synthesis of $\left[\mathrm{CuDy}(\mathrm{L} \cdot \mathrm{SMe})_{2}(\mathrm{OOCMe})_{2}\left(\mathrm{NO}_{3}\right)\right] \cdot 0.75 \mathrm{MeOH}(3)$. Compound 3 was synthesized following the procedure described for compound 1 , replacing $\mathrm{Gd}\left(\mathrm{NO}_{3}\right)_{3} \cdot 6 \mathrm{H}_{2} \mathrm{O}$ by $\operatorname{Dy}\left(\mathrm{NO}_{3}\right)_{3} \cdot 6 \mathrm{H}_{2} \mathrm{O}(0.115 \mathrm{~g}, 0.25 \mathrm{mmol})$. Yield of the air-dried crystals: $0.176 \mathrm{~g}$ (74.0 \%). Elemental analysis, calcd. for $\mathrm{C}_{34} \mathrm{Cu}_{1} \mathrm{H}_{34} \mathrm{Dy}_{1} \mathrm{~N}_{3} \mathrm{O}_{11} \mathrm{~S}_{2} \cdot 0.75 \mathrm{H}_{2} \mathrm{O} \quad\left(\mathrm{M}=950.82 \mathrm{~g} \cdot \mathrm{mol}^{-1}\right.$ without crystal solvent): C, 42.35; $\mathrm{H}, 3.71$ and N, $4.36 \%$. Found: C, 42.39; $\mathrm{H}, 3.64$ and N, $4.38 \%$ IR (KBr pellet), $\tilde{\mathrm{V}}_{\max } / \mathrm{cm}^{-1}: 3424$ (m, br), 3063 (w), 2982 (w), $2918(w), 2841(w), 1614(\mathrm{~s})$, 1560 (s), 1490 (sh), 1463 (s), 1449 (sh), 1414 (sh), 1341 (w), 1305 (s), 1238 (s), 1199 (s), 1094 (m), 1078 (m), 1048 (w), 1033 (w), $1013(\mathrm{w}), 971(\mathrm{~m}), 932(\mathrm{w}), 853(\mathrm{~m}), 824(\mathrm{~m}), 789$ $(\mathrm{w}), 741(\mathrm{~m}), 738(\mathrm{sh}), 712(\mathrm{w}), 680(\mathrm{~m}), 653(\mathrm{w}), 612(\mathrm{w})$, $585(\mathrm{~m}), 539(\mathrm{w}), 449(\mathrm{w}), 405(\mathrm{w})$. MS (MeCN, ESI): m/z = $630.068\left(\mathrm{C}_{30} \mathrm{Cu}_{1} \mathrm{H}_{28} \mathrm{Na}_{1} \mathrm{~N}_{2} \mathrm{O}_{4} \mathrm{~S}_{2}{ }^{+}, \quad 54 \% ; \quad\left[\mathrm{CuNa}(\mathrm{L} \cdot \mathrm{SMe})_{2}\right]^{+}\right)$, $889.059 \quad\left(\mathrm{C}_{34} \mathrm{Cu}_{1} \mathrm{H}_{34} \mathrm{Dy}_{1} \mathrm{~N}_{2} \mathrm{O}_{8} \mathrm{~S}_{2}{ }^{+}, \quad 52 \%\right.$; $\left.\left[\mathrm{CuDy}(\mathrm{L} \cdot \mathrm{SMe})_{2}(\mathrm{OOCMe})_{2}\right]^{+}\right), 944.109\left(\mathrm{C}_{45} \mathrm{Cu}_{2} \mathrm{H}_{42} \mathrm{~N}_{3} \mathrm{O}_{6} \mathrm{~S}_{3}{ }^{+}, 100\right.$ \%; $\left.\left[\mathrm{Cu}_{2}(\mathrm{~L} \cdot \mathrm{SMe})_{3}\right]^{+}\right), \quad 1102.095\left(\mathrm{C}_{47} \mathrm{Cu}_{1} \mathrm{H}_{45} \mathrm{Dy}_{1} \mathrm{~N}_{3} \mathrm{O}_{8} \mathrm{~S}_{3}{ }^{+}, \quad 56 \%\right.$; $\left.\left[\mathrm{CuDy}(\mathrm{L} \cdot \mathrm{SMe})_{3}(\mathrm{OOCMe})\right]^{+}\right)$.

Synthesis of $\left[\mathrm{CuY}(\mathrm{L} \cdot \mathrm{SMe})_{2}(\mathrm{OOCMe})_{2}\left(\mathrm{NO}_{3}\right)\right] \cdot \mathrm{MeOH}$ (4). Compound 4 was synthesized following the procedure described for compound 1 , replacing $\mathrm{Gd}\left(\mathrm{NO}_{3}\right)_{3} \cdot 6 \mathrm{H}_{2} \mathrm{O}$ by $\mathrm{Y}\left(\mathrm{NO}_{3}\right)_{3} \cdot 6 \mathrm{H}_{2} \mathrm{O}(0.096 \mathrm{~g}, 0.25 \mathrm{mmol})$. Yield of the air-dried crystals: $0.053 \mathrm{~g}$ (24.2 \%). Elemental analysis, calcd. for $\mathrm{C}_{34} \mathrm{Cu}_{1} \mathrm{H}_{34} \mathrm{Y}_{1} \mathrm{~N}_{3} \mathrm{O}_{11} \mathrm{~S}_{2} \cdot 0.5 \mathrm{H}_{2} \mathrm{O}\left(\mathrm{M}=877.23 \mathrm{~g} \cdot \mathrm{mol}^{-1}\right.$ without crystal solvent): $\mathrm{C}, 46.55 ; \mathrm{H}, 3.91$ and $\mathrm{N}, 4.79 \%$. Found: $\mathrm{C}, 46.13$; $\mathrm{H}, 3.73$ and N, $5.00 \%$ IR (KBr pellet), $\tilde{V}_{\max } / \mathrm{cm}^{-1}: 3432$ (W, br), $3062(w), 2981(w), 2921(w), 2849(w), 1613$ (vs), 1560 (s), 1490 (s), 1474 (vs), 1414 (m), 1383 (m), 1341 (vw), 1305 (s), 1238 (s), 1198 (s), 1095 (m), $1074(\mathrm{~m}), 1048$ (vw), 1034 (w), $1015(\mathrm{w}), 971(\mathrm{~m}), 933(\mathrm{vw}), 853(\mathrm{w}), 824(\mathrm{w}), 788(\mathrm{vw})$, $745(\mathrm{~m}), 712(\mathrm{w}), 681(\mathrm{w}), 652(\mathrm{w}), 614(\mathrm{vw}), 584(\mathrm{w}), 540$ (w), 448 (w). MS (MeCN, ESI): $\mathrm{m} / \mathrm{z}=630.068$ $\left(\mathrm{C}_{30} \mathrm{Cu}_{1} \mathrm{H}_{28} \mathrm{Na}_{1} \mathrm{~N}_{2} \mathrm{O}_{4} \mathrm{~S}_{2}{ }^{+}, \quad 20 \% ; \quad\left[\mathrm{CuNa}(\mathrm{L} \cdot \mathrm{SMe})_{2}\right]^{+}\right), \quad 814.012$ $\left(\mathrm{C}_{34} \mathrm{Cu}_{1} \mathrm{H}_{34} \mathrm{Y}_{1} \mathrm{~N}_{2} \mathrm{O}_{8} \mathrm{~S}_{2}^{+}, 100 \%\right.$; $\left.\quad\left[\mathrm{CuY}(\mathrm{L} \cdot \mathrm{SMe})_{2}(\mathrm{OOCMe})_{2}\right]^{+}\right)$, $944.083\left(\mathrm{C}_{45} \mathrm{Cu}_{2} \mathrm{H}_{42} \mathrm{~N}_{3} \mathrm{O}_{6} \mathrm{~S}_{3}^{+}, 100 \%\right.$; $\left.\left[\mathrm{Cu}_{2}(\mathrm{~L} \cdot \mathrm{SMe})_{3}\right]^{+}\right), 1027.073$ $\left.\left.\left(\mathrm{C}_{47} \mathrm{Cu}_{1} \mathrm{H}_{45} \mathrm{Y}_{1} \mathrm{~N}_{3} \mathrm{O}_{8} \mathrm{~S}_{3}{ }^{+}, 64 \% \text {; [CuY(L.SMe }\right)_{3}(\mathrm{OOCMe})\right]^{+}\right)$.

Synthesis of $\left[\mathrm{Cu}_{2} \mathrm{Na}(\mathrm{L} \cdot \mathrm{SMe})_{4}\right] \mathrm{NO}_{3} \cdot 3 \mathrm{MeOH}$ (5). Method A: Compound 1 ( $0.095 \mathrm{~g}, 0.1 \mathrm{mmol})$ was dissolved in $10 \mathrm{~mL}$ of methanol under refluxing conditions and $\mathrm{NaOMe}(0.014 \mathrm{~g}$, $0.26 \mathrm{mmol}$; alternatively: $\mathrm{NaN}_{3} 0.017 \mathrm{~g}, 0.26 \mathrm{mmol}$ ) was added to the brownish solution. The solution was stirred at $65{ }^{\circ} \mathrm{C}$ for 1 hour. The methanolic solution was filtered off and the filtrate was stored in a capped vial at room temperature. Dark brown needle-like single crystals of compound 5 were isolated after one day, washed with a small amount of ice-cold methanol and dried in air. Yield: $0.023 \mathrm{~g}$ (34.9\%, based on $\mathrm{Cu}$, no solvent). Method B: The Schiff base $\mathrm{HL} \cdot \mathrm{SMe}(0.137 \mathrm{~g}, 0.5 \mathrm{mmol})$ was dissolved in $10 \mathrm{~mL}$ of methanol and triethylamine $(0.08 \mathrm{~mL}, 0.58 \mathrm{mmol})$ was introduced into the solution. $\mathrm{Cu}\left(\mathrm{NO}_{3}\right)_{2} \cdot 3 \mathrm{H}_{2} \mathrm{O}(0.061 \mathrm{~g}, 0.25 \mathrm{mmol})$ was added, which gave a dark brown color. After stirring at $65{ }^{\circ} \mathrm{C}$ for 15 minutes NaOMe (0.014g, $0.26 \mathrm{mmol}$ ) was added, and the methanolic solution was then stirred under refluxing conditions for further 30 minutes. The solution was filtered off and the filtrate was stored in a capped vial at room temperature. Dark brown needle-like single crystals of compound $\mathbf{5}$ were isolated after one day, washed with a small amount of ice cold methanol and dried in air. Yield: $0.033 \mathrm{~g}$ (20.0\%, based on $\mathrm{Cu}$ ). Elemental analysis, calcd. for $\mathrm{C}_{60} \mathrm{Cu}_{2} \mathrm{H}_{56} \mathrm{~N}_{5} \mathrm{Na}_{1} \mathrm{O}_{11} \mathrm{~S}_{4} \cdot \mathrm{H}_{2} \mathrm{O} \quad\left(\mathrm{M}=1319.47 \mathrm{~g} \cdot \mathrm{mol}^{-1}\right.$ disregarding solvent): C, 54.62; H, 4.43 and N, 5.31\%. Found: C, 54.23; H, 4.51 and N, $5.15 \%$. IR (KBr pellet), $\tilde{V}_{\text {max }} / \mathrm{cm}^{-1}: 3424$ (m, br), 2918 (w), 2829 (w), 1606 (vs), 1581 (sh), 1542 (s), 1408 (s), 1466 (s), 1434 (s), 1382 (m), 1325 (s), 1236 (vs), 1191 (vs), $1107(\mathrm{~m}), 1091(\mathrm{~m}), 1076(\mathrm{~m}), 1011(\mathrm{w}), 981(\mathrm{~m}), 853(\mathrm{~m})$, $821(\mathrm{~m}), 740(\mathrm{~m}), 710(\mathrm{sh}), 683(\mathrm{w}), 578(\mathrm{~m}), 539(\mathrm{w})$, 441(w). MS (MeCN, ESI): $\mathrm{m} / \mathrm{z}=630.067$ $\left(\mathrm{C}_{30} \mathrm{Cu}_{1} \mathrm{H}_{28} \mathrm{~N}_{2} \mathrm{Na}_{1} \mathrm{O}_{4} \mathrm{~S}_{2}{ }^{+}, \quad 100 \% ; \quad\left[\mathrm{CuNa}(\mathrm{L} \cdot \mathrm{SMe})_{2}\right]^{+}\right), \quad 944.083$ $\left(\mathrm{C}_{45} \mathrm{Cu}_{2} \mathrm{H}_{42} \mathrm{~N}_{3} \mathrm{O}_{6} \mathrm{~S}_{3}{ }^{+}, \quad 4 \quad \% ; \quad\left[\mathrm{Cu}_{2}(\mathrm{~L} \cdot \mathrm{SMe})_{3}\right]^{+}\right), \quad 1239.144$ $\left(\mathrm{C}_{60} \mathrm{Cu}_{2} \mathrm{H}_{56} \mathrm{~N}_{4} \mathrm{Na}_{1} \mathrm{O}_{8} \mathrm{~S}_{4}{ }^{+}, 50 \%\right.$; $\left.\left[\mathrm{Cu}_{2} \mathrm{Na}(\mathrm{L} \cdot \mathrm{SMe})_{4}\right]^{+}\right)$.

X-ray crystallography. Single-crystal diffraction data were collected on a Bruker APEX II CCD diffractometer at $100 \mathrm{~K}$ for 1 and on a SuperNova (Agilent Technologies) diffractometer at $120 \mathrm{~K}$ for 2-6 and $\mathrm{HL} \cdot \mathrm{SMe}$ with MoK $\alpha$ radiation ( $\lambda=0.71073 \AA$ ) for all the compounds except 4, for which CuK $\alpha$ radiation $(\lambda=1.54184 \AA$ ) has been used. The crystals were mounted in a Hampton cryoloop with Paratone-N oil to prevent water loss. Absorption corrections for $\mathbf{1}$ were applied empirically using the SADABS program..$^{52}$ Absorption corrections for 2-6 and $\mathrm{HL} \cdot \mathrm{SMe}$ were done numerically based on multifaceted crystal model using CrysAlis software. ${ }^{53}$ The structures were solved by direct methods and refined by full-matrix least-squares method against $|F|^{2}$ with anisotropic thermal parameters for all non-hydrogen atoms (Gd, Dy, Tb, Y, Cu, S, O, N and C) employing the SHELXTL software package. ${ }^{54}$ ISOR restrictions had to be applied for some carbons. Hydrogen atoms of the complexes and the ligand $\mathrm{HL} \cdot \mathrm{SMe}$ were placed in geometrically calculated positions, while the hydrogen atoms of the disordered solvent $\mathrm{CH}_{3} \mathrm{OH}$ molecules (in 1-5) were not located.

The relative site occupancy factors for the disordered positions of carbon and oxygen atoms of co-crystallized methanol molecules in 1-5 were first refined in an isotropic approximation with $U_{\text {iso }}=0.05$ and then fixed at the obtained values and refined without the thermal parameters restrictions. The relative occupancies of the disordered $\mathrm{C}_{6} \mathrm{H}_{4}-\mathrm{S}-\mathrm{CH}_{3}$ moieties in 3 were refined using a combination of PART and EADP (for the heaviest $S$ atoms) commands.

The relatively high residual electron density in the structure of $3\left(2.404 \mathrm{e}^{-3}\right)$ is located in the proximity of the Dy1 center $(0.87 \AA)$. The surprisingly high residual electron density maximum $\left(3.61 \mathrm{e}^{-3}\right)$ in the structure 6 cannot be reasonably assigned to any atom (e. g. solvent oxygen) due to its very small distance to carbon atoms of the complexes, $\mathrm{C} 204$ (1.538 $\AA$ ) and C205 (1.789 $\AA$ ). This apparently corresponds to some residual absorption artefacts.

Additional crystallographic data are summarized in Tables S2 and S3. Further details on the crystal structures investigation can be obtained, free of charge, on application to CCDC, 12 Union Road, Cambridge CB2 1EZ, UK: http://www.ccdc.cam.ac.uk/, e-mail: da- 
ta_request@ccdc.cam.ac.uk, or fax: +441223 336033 upon quoting 1530688 (1), 1530689 (2), 1530690 (3), 1530691 (4), 1530692 (5), 1530693 (6) and 1530694 (HL.SMe) numbers.

Magnetic susceptibility measurements. Magnetic susceptibility data of compounds 1-5 were recorded using a Quantum Design MPMS-5XL SQUID magnetometer for direct current (dc) and alternating current (ac) measurements. The polycrystalline samples were compacted and immobilized into cylindrical PTFE capsules. The dc susceptibility data were acquired as a function of the field (0.1-5.0 T) and temperature (2.0-290 K). The ac susceptibility data were measured in the absence of a static bias field in the frequency range $10-1000 \mathrm{~Hz}\left(T=2.0-50 \mathrm{~K}, B_{\mathrm{ac}}=3 \mathrm{G}\right)$, but no out-of-phase signals were observed. The data were corrected for diamagnetic contributions from the sample holder and the compounds $\left(\chi_{\mathrm{m} \text {, dia }} / 10^{-4} \mathrm{~cm}^{3} \mathrm{~mol}^{-1}, \mathbf{1 :}-4.76,2\right.$ : $-4.82,3:-4.91,4:-4.07,5:-4.83)$.

IRRAS measurements. IRRAS measurements were performed on a FT-IR spectroscope Vertex 70, Bruker Optics equipped with a high-sensitivity $\mathrm{Hg}-\mathrm{Cd}-\mathrm{Te}(\mathrm{MCT})$ detector and an A513/Q variable angle reflection accessory including an automatic rotational holder for MIR polarizer. The IR beam was polarized with a KRS-5 polarizer with $99 \%$ degree of polarization. Double-sided interferograms were collected with a sample frequency of $20 \mathrm{kHz}$, an aperture of $1.5 \mathrm{~mm}$ and a nominal spectral resolution of $4 \mathrm{~cm}^{-1}$. The interferograms were apodized by a Blackmann-Harris 3-term apodization and zero-filled with a zerofilling factor of 2 . The angle of incidence was set to $80^{\circ}$, and p-polarized IR radiation was used to record the spectra. For the background measurements, the sample chamber was purged with argon for 5 min, then 1024 scans were collected while continuing to purge. For the sample measurements, argon purging was started at the moment the first scan was recorded. The scans were averaged until the peaks arising from the water vapor in the sample chamber were compensated, for what typically 800-1500 scans were necessary. The spectra were processed using the OPUS software (Bruker). Where necessary, scatter correction was applied to the spectra.

General procedure for the preparation of Au substrates for IRRAS. The gold substrates were fabricated by sputtering a $10 \mathrm{~nm}$ adhesive film of $\mathrm{Ti}$ and $\mathrm{a} 100 \mathrm{~nm}$ thick layer of Au on $<100>$ oriented silicon wafers with a native $\mathrm{SiO}_{2}$ layer. The freshly prepared gold substrates were cleaned in oxygen plasma $\left[p\left(\mathrm{O}_{2}\right)=0.4 \mathrm{mbar}, f=40 \mathrm{kHz}\right.$ and $\left.P=75 \mathrm{~W}\right]$ for $4 \mathrm{~min}$ immediately prior to the deposition of molecules. The compounds studied by IRRAS were prepared for the deposition as follows: a solution ( $\sim 1.0 \mathrm{mmolar})$ of $\mathrm{HL} \cdot \mathrm{SMe}$ was prepared using absolute ethanol and a solution of compound 2 using methanol GPR Rectapur (purity: $100 \%$ ). The Au substrates were stored for $24 \mathrm{~h}$ in the solutions and dried for 24 $\mathrm{h}$ in a desiccator.

DFT calculations. Transport properties of complexes $\mathbf{1}$ and $\mathbf{4}$ were studied using a combination of DFT and EGF. The mean-field Hamiltonian of both complexes was constructed using the SIESTA (Spanish Initiative for Electronic Simulations with Thousands of Atoms) code. ${ }^{55,56}$ The generalizedgradient approximation (GGA) functional expression of
Perdew, Burke and Ernzerhof (PBE) $)^{57}$ was employed and valence pseudopotentials were generated according to the method suggested by Troullier and Martins ${ }^{58}$ except for gold, where 1-electron pseudopotential was employed instead. Note that this pseudopotential gives incorrect structures if it is used for geometry optimization but reasonable transport properties in single-point calculations. A double-zeta basis set with polarization functions was used for all elements. Gollum code was exploited to perform the post-processing transport calculations. ${ }^{59}$ The DFTHamiltonian and overlap matrices were mapped into a tight-binding scheme to compute the coherent transport properties. The EGF is the non-self-consistent method that presents a good compromise between accuracy and computational cost. $^{60}$

\section{ASSOCIATED CONTENT}

Supporting Information. Synthesis and characterization of compound 6; analytical data of HL.SMe; IR spectra of compounds 1-5 and IRRAS spectra of compound 2; crystal data and structure refinement details for compounds 1-6 and $\mathrm{HL} \cdot \mathrm{SMe}$; a comparative analysis of structural data between compounds $\mathbf{1}-\mathbf{5}$ and related complexes described in the literature; measured ESI-MS spectra of compounds 1-5; calculated isotopic pattern of compounds 1-5; TGA curves of compounds 1-5; details of large-area transport measurements. This material is available free of charge via the Internet at http://pubs.acs.org.

\section{AUTHOR INFORMATION}

\author{
Corresponding Author \\ * E-mails: kirill.monakhov@ac.rwth-aachen.de, \\ paul.koegerler@ac.rwth-aachen.de, \\ r.c.chiechi@rug.nl, \\ eliseo.ruiz@qi.ub.edu.
}

\section{Notes}

The authors declare no competing financial interest.

\section{ACKNOWLEDGEMENTS}

K.Y.M. thanks the Excellence Initiative of the German federal and state governments for an RWTH Start-Up grant. The authors are grateful to Ullrich Englert (RWTH Aachen University) for X-ray crystallographic assistance and Ulrich Simon (RWTH Aachen University) for access to the IRRAS equipment. We also thank Henrika Hüppe (RWTH Aachen University) for the crystallization of compound 6. E.R. thanks to the Generalitat de Catalunya for an ICREA Academia award and the 2017SGR1289 grant, to the Spanish Ministerio de Economía y Competitividad for FPI grant of A.M.R. and the funding of the CTQ2015-64579-C3-1-P, MINECO/FEDER, UE project. E.R. also acknowledges the BSC supercomputer center for computational resources.

\section{REFERENCES}


(1) Zhang, X.; N'Diaye, A. T.; Jiang, X.; Zhang, X.; Yin, Y.; Chen, X.; Hong, X.; Xu, X.; Dowben, P. A. Indications of magnetic coupling effects in spin cross-over molecular thin films. Chem. Commun. 2018, 54, 944-947.

(2) Mannini, M.; Pineider, F.; Danieli, C.; Totti, F.; Sorace, L.; Sainctavit, Ph.; Arrio, M.-A.; Otero, E.; Joly, L.; Cezar, J. C.; Cornia, A.; Sessoli, R. Quantum tunnelling of the magnetization in a monolayer of oriented single-molecule magnets. Nature 2010, 468, 417421.

(3) Rocha, A. R.; García-Suárez, V. M.; Bailey, S. W.; Lambert, C. J.; Ferrer, J.; Sanvito, S. Towards molecular spintronics. Nat. Mater. 2005, 4, 335-339.

(4) Bogani, L.; Wernsdorfer, W. Molecular spintronics using singlemolecule magnets. Nat. Mater. 2008, 7, 179-186.

(5) Dreiser, J. Molecular lanthanide single-ion magnets: from bulk to submonolayers. J. Phys.: Condens. Matter 2015, 27, 183203183222.

(6) Camarero, J.; Coronado, E. Molecular vs. inorganic spintronics: the role of molecular materials and single molecules. J. Mater. Chem. 2009, 19, 1678-1684.

(7) Engelkes, V. B.; Beebe, J. M; Frisbie, C. D. Length-dependent transport in molecular junctions based on SAMs of alkanethiols and alkanedithiols: Effect of metal work function and applied bias on tunneling efficiency and contact resistance. J. Am. Chem. Soc. 2004, 126, 14287-14296.

(8) Higgins, S. J.; Nichols, R. J. Metal/molecule/metal junction studies of organometallic and coordination complexes; What can transition metals do for molecular electronics? Polyhedron 2018, 140, 25-34.

(9) Aragonès, A. C.; Aravena, D.; Cerdá, J. I.; Acís-Castillo, Z.; Li, H.; Real, J. A.; Sanz, F.; Hihath, J.; Ruiz, E.; Díez-Pérez, I. Large conductance switching in a single-molecule device through room temperature spin-dependent transport. Nano Lett. 2016, 16, 218226.

(10) Chiechi, R. C.; Weiss, E. A.; Dickey, M. D.; Whiteside, G. M. Eutectic Gallium-Indium (EGaln): A moldable liquid metal for electrical characterization of self-assembled monolayers. Angew. Chem. Int. Ed. 2008, 47, 142-144.

(11) Wan, A.; Sangeeth, C. S. S.; Wang, L.; Yuan, L.; Jiang, L.; Nijhuis, C. A. Arrays of high quality SAM-based junctions and their application in molecular diode based logic. Nanoscale 2015, 7, 1954719556.

(12) Zhang, Y.; Qiu, X.; Gordiichuk, P.; Soni, S.; Krijger, T. L.; Herrmann, A.; Chiechi, R. C. Mechanically and electrically robust self-assembled monolayers for large-area tunneling junctions. J. Phys. Chem. C 2017, 121, 14920-14928.

(13) Carlotti, M.; Kovalchuk, A.; Wächter, T.; Qiu, X.; Zharnikov, M.; Chiechi, R. C. Conformation-driven quantum interference effects mediated by through-space conjugation in self-assembled monolayers. Nat. Commun. 2016, 7, 13904-13910.

(14) Frisenda, R.; Janssen, V. A. E. C.; Grozema, F. C.; van der Zant, H. S. J.; Renaud, N. Mechanically controlled quantum interference in individual $\pi$-stacked dimers. Nat. Chem. 2016, 8, 1099-1104.

(15) Qi, Y.; Ratera, I.; Park, J. Y.; Ashby, P. D.; Quek, S. Y.; Neaton, J. B.; Salmeron, M. Mechanical and charge transport properties of alkanethiol self-assembled monolayers on a Au(111) surface: The role of molecular tilt. Langmuir 2008, 24, 2219-2223.

(16) Wu, J.; Li, X.-L.; Guo, M.; Zhao, L.; Zhang, Y.-Q.; Tang, J. Realization of toroidal magnetic moments in heterometallic $3 \mathrm{~d}-4 \mathrm{f}$ metallocycles. Chem. Commun. 2018, 54, 1065-1068.

(17) Biswas, S.; Bag, P.; Das, S.; Kundu, S.; van Leusen, J.; Kögerler, P.; Chandrasekha, V. Heterometallic $\left[\mathrm{Cu}_{2} \mathrm{Ln}_{3}\right]\left(\mathrm{Ln}=\mathrm{Dy}{ }^{\text {III }}, \mathrm{Gd}^{\text {III }}\right.$ and $\left.\mathrm{Ho}^{\prime \prime \prime}\right)$ and $\left[\mathrm{Cu}_{4} \mathrm{Ln}_{2}\right]\left(\mathrm{Ln}=\mathrm{Dy}^{\text {III }}\right.$ and $\left.\mathrm{Ho}^{\prime \prime \prime}\right)$ compounds: Synthesis, structure, and magnetism. Eur. J. Inorg. Chem. 2017, 1129-1142.

(18) Baskar, V.; Gopal, K.; Helliwell, M.; Tuna, F.; Wernsdorfer, W.; Winpenny, R. E. P. 3d-4f Clusters with large spin ground states and SMM behavior. Dalton Trans. 2010, 39, 4747-4750.
(19) Li, Z.-Y.; Yang, J.-S.; Liu, R.-B.; Zhang, J.-J.; Liu, S.-Q.; Ni, J.; Duan, C.-Y. Two one-dimensional compounds based on pyramidal $\left\{\mathrm{TbCu}_{4}\right\}$ units and formate ligand: chair-like $\left[\left(\mathrm{H}_{2} \mathrm{O}\right)_{2}\left(\mathrm{ClO}_{4}\right)_{2}\right]^{2-}$ clusters and slow relaxation of magnetization. Dalton Trans. 2012, 41, 13264-13266.

(20) Li, Z.-Y.; Wang, Y.-X.; Zhu, J.; Liu, S.-Q.; Xin, G.; Zhang, J.-J.; Huang, H.-Q.; Duan, C.-Y. Three series of $3 \mathrm{~d}-4 \mathrm{f}$ heterometallic polymers based on $\left[\mathrm{LnCu}_{6}\right]$ or $\left[\mathrm{Ln}_{6} \mathrm{Cu}_{24}\right]$ clusters and formate bridges: Displaying significant magnetocaloric effect. Cryst. Growth Des. 2013, 13, 3429-3437.

(21) Xiong, G.; Xu, H.; Cui, J.-Z.; Wang, Q.-L.; Zhao, B. The multiple core-shell structure in $\mathrm{Cu}_{24} \mathrm{Ln}_{6}$ cluster with magnetocaloric effect and slow magnetization relaxation. Dalton Trans. 2014, 43, 56395642 .

(22) Zhuang, G.-L.; Chen, W.-X.; Zhao, H.-X.; Kong, X.-J.; Long, L.-S.; Huang, R.-B.; Zheng, L.-S. Two three-dimensional 2p-3d-4f heterometallic frameworks featuring a $\mathrm{Ln}_{6} \mathrm{Cu}_{24} \mathrm{Na}_{12}$ cluster as a node. Inorg. Chem. 2011, 50, 3843-3845.

(23) Zhang, J.-J.; Hu, S.-M.; Xiang, S.-C.; Sheng, T.; Wu, X.-T.; Li, Y.$M$. Syntheses, structures, and properties of high-nuclear $3 \mathrm{~d}-4 \mathrm{f}$ clusters with amino acid as ligand: $\left\{\mathrm{Gd}_{6} \mathrm{Cu}_{24}\right\},\left\{\mathrm{Tb}_{6} \mathrm{Cu}_{26}\right\}$, and $\left\{\left(\mathrm{Ln}_{6} \mathrm{Cu}_{24}\right)_{2} \mathrm{Cu}\right\}(\mathrm{Ln}=\mathrm{Sm}, \mathrm{Gd})$. Inorg. Chem. 2006, 45, 7173-7181.

(24) Ueno, T.; Fujinami, T.; Matsumoto, N.; Furusawa, M.; Irie, R.; Re, N.; Kanetomo, T.; Ishida, T.; Sunatsuk, Y. Circular and chainlike copper(II)-lanthanide(III) complexes generated by assembly reactions of racemic and chiral copper(II) cross-linking ligand complexes with $\mathrm{Ln}^{\prime \prime \prime}\left(\mathrm{NO}_{3}\right)_{3} \cdot 6 \mathrm{H}_{2} \mathrm{O}\left(\mathrm{Ln}^{\mathrm{III}}=\mathrm{Gd}^{\prime \prime \prime}, \mathrm{Tb}^{\text {III}}, \mathrm{Dy} \mathrm{y}^{\mathrm{III}}\right)$. Inorg. Chem. 2017, 56, 1679-1695.

(25) Kondinski, A.; Monakhov, K. Yu. Breaking the Gordian knot in the structural chemistry of polyoxometalates: Copper(II)oxo/hydroxo clusters. Chem. Eur. J. 2017, 23, 7841-7852.

(26) Schmitz, S.; van Leusen, J.; Izarova, N. V.; Lan, Y.; Wernsdorfer, W.; Kögerler, P.; Monakhov, K. Yu. Supramolecular 3d-4f single-molecule magnet architectures. Dalton Trans. 2016, 45, 16148-16152.

(27) Schmitz, S.; van Leusen, J.; Ellern, A.; Kögerler, P.; Monakhov, K. Yu. A thioether-decorated $\left\{\mathrm{Mn}_{11} \mathrm{~Tb}_{4}\right\}$ coordination cluster with slow magnetic relaxation. Inorg. Chem. Front. 2015, 2, 1095-1100.

(28) Lueken, H. Magnetochemie, Teubner, Stuttgart, 1999.

(29) Speldrich, M.; Schilder, H.; Lueken, H.; Kögerler, P. A Computational framework for magnetic polyoxometalates and molecular spin structures: CONDON 2.0. Isr. J. Chem. 2011, 51, 215-227.

(30) van Leusen, J.; Speldrich, M.; Schilder, H.; Kögerler, P. Comprehensive insight into molecular magnetism via CONDON: Full vs. effective models. Coord. Chem. Rev. 2015, 289-290, 137-148.

(31) Griffith, J. S. The theory of transition metal ions, Cambridge University Press, Cambridge, 1980.

(32) Condon, E. U.; Shortley, G. H. The theory of atomic spectra, Cambridge University Press, Cambridge, 1970.

(33) Sutter, J.-P.; Kahn, M. L. Lanthanide ions in molecular exchange coupled systems, in Magnetism: Molecules to materials V (Eds.: J. S. Miller, M. Drillon), Wiley-VCH, Weinheim, 2005.

(34) Schmitz, S.; van Leusen, J.; Izarova, N. V.; Bourone, S. D. M.; Ellern, A.; Kögerler, P.; Monakhov, K. Yu. Triangular $\left\{\mathrm{Ni}_{3}\right\}$ coordination cluster with a ferromagnetically coupled metal-ligand core. Polyhedron 2018, 144, 144-151.

(35) Allara, D. L.; Baca, A.; Pryde, C. A. Distortions of band shapes in external reflection infrared spectra of thin polymer films on metal substrates. Macromolecules 1978, 11, 1215-1220.

(36) Socrates, G. Infrared and Raman characteristic group frequencies; John Wiley \& Sons: Chichester, U.K., 2001.

(37) Thuo, M. M.; Reus, W. F.; Nijhuis, C. A.; Barber, J. R.; Kim, C.; Schulz, M. D.; Whitesides, G. M. Odd-even effects in charge transport across self-assembled monolayers. J. Am. Chem. Soc. 2011, 133, 2962-2975.

(38) Castañeda Ocampo, O. E.; Gordiichuk, P.; Catarci, S.; Gautier, D. A.; Herrmann, A.; Chiechi, R. C. Mechanism of orientation- 
dependent asymmetric charge transport in tunneling junctions comprising photosystem I. J. Am. Chem. Soc. 2015, 137, 8419-8427.

(39) Weiss, E. A.; Kaufman, G. K.; Kriebel, J. K.; Li, Z.; Schalek, R.; Whitesides, G. M. Si/SiO ${ }_{2}$-templated formation of ultraflat metal surfaces on glass, polymer, and solder supports: Their use as substrates for self-assembled monolayers. Langmuir 2007, 23, 9686-9694.

(40) Reus, W. F.; Thuo, M. M.; Shapiro, N. D.; Nijhuis, C. A.; Whitesides, G. M. The SAM, not the electrodes, dominates charge transport in metal-monolayer $/ / \mathrm{Ga}_{2} \mathrm{O}_{3} / \mathrm{Gallium}$-Indium Eutectic junctions. ACS Nano 2012, 6, 4806-4822.

(41) Beebe, J. M.; Kim, B. S.; Gadzuk, J. W.; Frisbie, C. D.; Kushmerick, J. G. Transition from direct tunneling to field emission in metalmolecule-metal junctions. Phys. Rev. Lett. 2006, 97, 026801026804.

(42) Ricœur, G.; Lenfant, S.; Guérin, D.; Vuillaume, D. Molecule/electrode interface energetics in molecular junction: A "transition voltage spectroscopy" study. J. Phys. Chem. C 2012, 116, 20722-20730.

(43) Kovalchuk, A.; Abu-Husein, T.; Fracasso, D.; Egger, D. A.; Zojer, E.; Zharnikov, M.; Terfort, A.; Chiechi, R. C. Transition voltages respond to synthetic reorientation of embedded dipoles in selfassembled monolayers. Chem. Sci. 2016, 7, 781-787.

(44) Garrigues, A. R.; Yuan, L.; Wang, L.; Mucciolo, E. R.; Thompon, D.; del Barco, E.; Nijhuis, C. A. A single-level tunnel model to account for electrical transport through single molecule- and selfassembled monolayer-based junctions. Sci. Rep. 2016, 6, 2651726531.

(45) Lavrich, D. J.; Wetterer, S. M.; Bernasek, S. L.; Scoles, G. Physisorption and chemisorption of alkanethiols and alkyl sulfides on Au(111). J. Phys. Chem. B 1998, 102, 3456-3465.

(46) Huisman, B.-H.; Rudkevich, D. M.; van Veggel, F. C. J. M.; Reinhoudt, D. N. Self-assembled monolayers of carceplexes on gold. J. Am. Chem. Soc. 1996, 118, 3523-3524.

(47) van Velzen, E. U. T.; Engbersen, J. F. J.; Reinhoudt, D. N. Selfassembled monolayers of receptor adsorbates on gold: Preparation and characterization. J. Am. Chem. Soc. 1994, 116, 3597-3598.

(48) Jiang, L.; Sangeeth, C. S. S.; Yuan, L.; Thompson, D.; Nijhuis, C. A. One-nanometer thin monolayers remove the deleterious effect of substrate defects in molecular tunnel junctions. Nano Lett. 2015, 15, 6643-6649.

(49) Baghbanzadeh, M.; Simeone, F. C.; Bowers, C. M.; Liao, K.-C.; Thuo, M.; Baghbanzadeh, M.; Miller, M. S.; Carmichael, T. B.; Whitesides, G. M. Odd-even effects in charge transport across nalkanethiolate-based SAMs. J. Am. Chem. Soc. 2014, 136, 16919-16925.

(50) Atanasov, M.; Aravena, D.; Suturina, E.; Bill, E.; Maganas, D.; Neese, F. First principles approach to the electronic structure, magnetic anisotropy and spin relaxation in mononuclear $3 \mathrm{~d}$ transition metal single molecule magnets. Coord. Chem. Rev. 2015, 289, 177-214.

(51) Fahrendorf, S.; Atodiresei, N.; Besson, C.; Caciuc, V.; Matthes, F.; Blügel, S.; Kögerler, P.; Bürgler, D. E.; Schneider, C. M. Accessing 4f-states in single-molecule spintronics. Nature Commun. 2013, 4, 2425.

(52) APEX2 (Version 1.08), SAINT (Version 7.03), SADABS (Version

2.11). Bruker advanced $X$-ray solutions, Madison (WI, USA).

(53) CrysAlisPro, Agilent Technologies, 1.171.36.28 (release 01-022013 CrysAlis171 .NET).

(54) Sheldrick, G. M. A short history of SHELX. Acta Cryst. 2008, A64, 112-122.

(55) Soler, J. M.; Artacho, E.; Gale, J. D.; García, A.; Junquera, J.; Ordejón, P.; Sánchez-Portal, D. The SIESTA method for $a b$ initio order-N materials simulation. J. Phys. Cond. Matter 2002, 14, 27452779.

(56) Sánchez-Portal, D.; Ordejón, P.; Canadell, E. Principles and applications of density functional theory in inorganic chemistry II,
Structure and bonding series, Springer, Berlin, 2004, vol. 113, 103170.

(57) Perdew, J. P.; Burke, K.; Ernzerhof, M. Generalized gradient approximation made simple. Phys. Rev. Lett. 1996, 77, 3865-3868.

(58) Trouiller, N.; Martins, J. L. Efficient pseudopotentials for plane-wave calculations. Phys. Rev. B 1991, 43, 1993-2006.

(59) Ferrer, J.; Lambert, C. J.; García-Suárez, V. M.; Manrique, D. Z.; Visontai, D.; Oroszlany, L.; Rodríguez-Ferradas, R.; Grace, I.; Bailey, S. W. D.; Gillemot, K.; Sadeghi, H.; Algharagholy, L. A. GOLLUM: A next-generation simulation tool for electron, thermal and spin transport. New J. Phys. 2014, 16, $093029-093094$.

(60) Martín-Rodríguez, A.; Aravena, D.; Ruiz, E. DFT approaches to transport calculations in magnetic single-molecule devices. Theor. Chem. Acc. 2016, 135, 192. 


\section{Table of Contents synopsis}

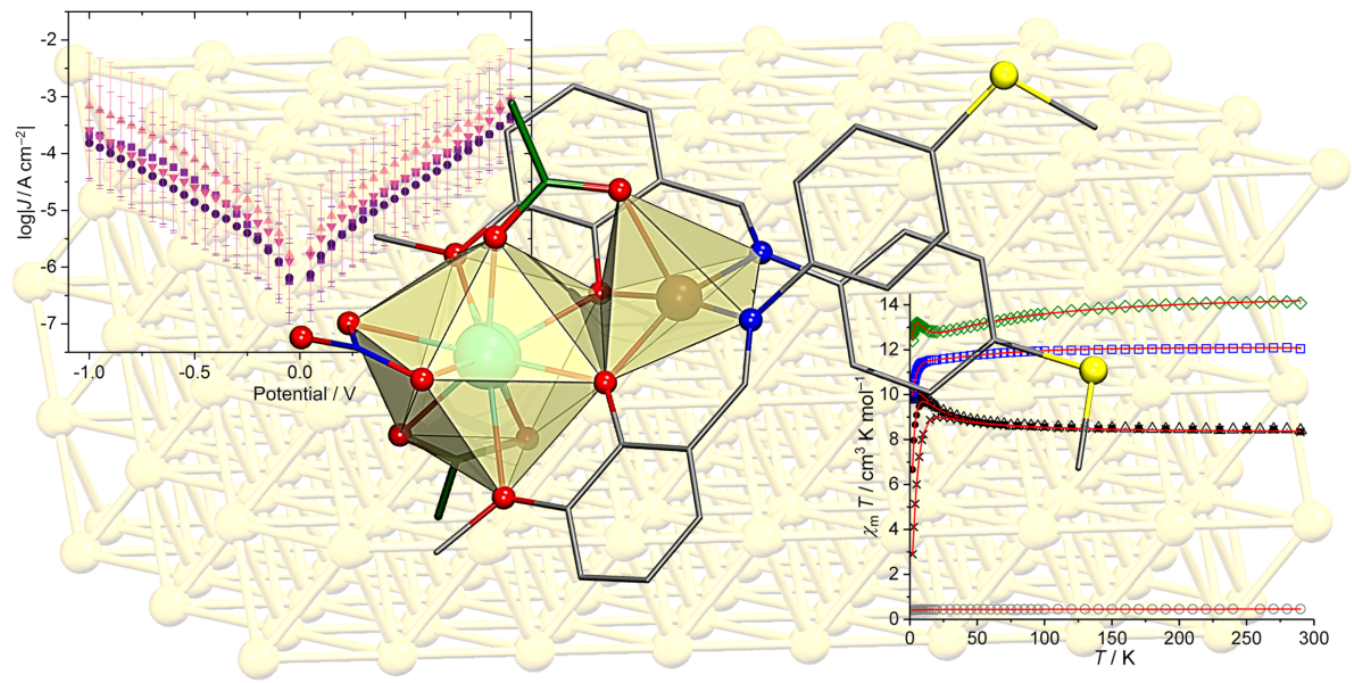

The molecular conductivity of charge-neutral dinuclear $3 \mathrm{~d}-4 \mathrm{f}$ coordination complexes that self-assemble into robust monolayers on gold electrodes highlights the distinct role of the metal ions in their molecular charge transport characteristics. 